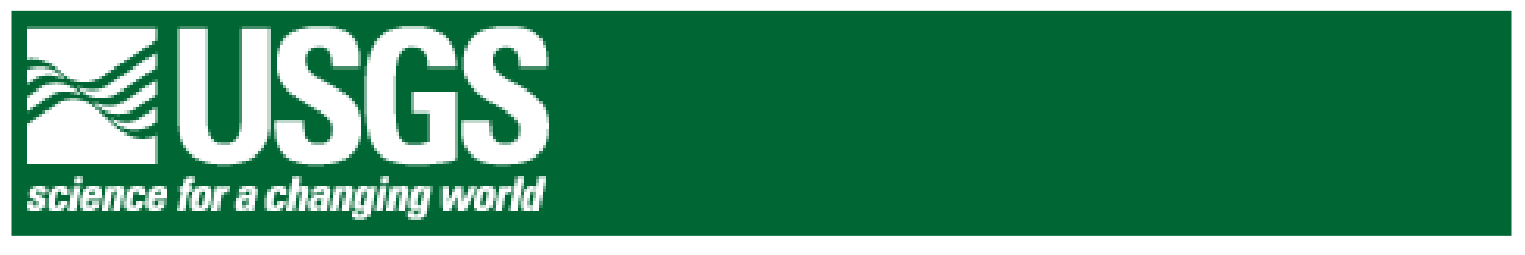

\title{
The Memphis, Shelby County, Tennessee, Seismic Hazard Maps
}

By Chris H. Cramer, Joan S. Gomberg, Eugene S. Schweig, Brian A. Waldron, and Kathleen Tucker

This report is preliminary and has not been reviewed for conformity with the U.S. Geological Survey editorial standards or with the North American Stratigraphic Code. Any use of trade, firm, or product names is for descriptive purposes only and does not imply endorsement by the U.S. Government.

\section{U.S. Geological Survey Open-File Report 04-1294}

\author{
U.S. DEPARTMENT OF THE INTERIOR \\ U.S. GEOLOGICAL SURVEY
}




\title{
The Memphis, Shelby County, Tennessee, Seismic Hazard Maps
}

\author{
By Chris H. Cramer, Joan S. Gomberg, Eugene S. Schweig, Brian A. Waldron, and \\ Kathleen Tucker
}

$\begin{array}{lr}\text { Introduction } & 1 \\ \text { Methodology } & 1 \\ \text { Characterizing the Shallow Geology } & 3 \\ \text { Site-Specific Amplification and Attenuation } & 4 \\ \text { Hazard Maps } & 7 \\ \text { Uncertainties } & 8 \\ \text { Summary } & 10 \\ \text { Acknowledgements } & 11 \\ \text { References } & 12 \\ \text { Tables } & 15 \\ \text { Figure Captions } & 17 \\ \text { Figures } & 20\end{array}$

\section{Introduction}

Memphis, Shelby County, Tennessee, is located where damaging earthquakes are only moderately likely, but the consequences of earthquakes, mainly from the New Madrid seismic zone, can be very high. This densely populated urban area is built on a 1kilometer-thick sequence of sediments deposited in a trough known as the Mississippi embayment. This thick pile of sediments significantly affects earthquake ground motions. We, the authors, have generated a suite of seismic hazard maps for a six-quadrangle area (fig. 1) in Memphis, Shelby County, Tennessee, that accounts for these effects. These maps and their derivative products represent the collaborative efforts of the U.S. Geological Survey (USGS) and its partners. Herein, we document how these seismic hazard maps (probabilistic and scenario) were generated. The Memphis maps complement the USGS national seismic hazard maps (Frankel and others, 2002), which do not include the effects of local geologic structure. Otherwise, both sets of maps use the same information and methodology. We emphasize that the Memphis maps are regional in nature and should not be used for site-specific analyses or as a basis for structural design.

\section{Methodology}

The methodology developed to generate the Memphis seismic hazard maps builds on that used for the USGS national seismic hazard maps (Frankel and others, 2002). Unlike the national maps, our approach also includes the effects of local sediment structure in such a way that fully preserves the probabilistic nature of the maps (Cramer, 2003). Probabilistic maps express the hazard in terms of the levels of horizontal ground shaking that have a specified chance of being exceeded in a given time period. The general state of practice in calculating a site-specific probabilistic ground motion has 
been to calculate a probabilistic bedrock ground motion and then to multiply it by a deterministic site-amplification factor. If the site-amplification factor has no uncertainty (unlikely!), the resulting site-specific ground motion would still be a probabilistic result. The site-amplification factor, however, typically represents the median value from some distribution so that the resulting ground motion is a hybrid answer that is no longer completely probabilistic. In other words, the ground motions estimated using this stateof-practice approach will not have the probability specified for the bedrock ground motions, and at large ground motions (greater $0.3 \mathrm{~g}-\mathrm{g}$ is the acceleration of gravity at the earth's surface) will underestimate the true probability of exceedance. For example, ground-motion estimates for a 2\%-in-50-year (1 in 2,475 annual) probability of exceedance made using a completely probabilistic approach will be about 10 percent greater than those estimated by simply multiplying a bedrock probabilistic ground motion by a median site-amplification factor. This difference will be even larger at smaller probabilities of exceedance. In addition, the completely probabilistic hazard explicitly incorporates the uncertainty in our knowledge of site amplification of ground motions in the estimates.

Generally, site-specific amplification is developed from geological, geophysical, and geotechnical subsurface information (Kramer, 1996). A soil profile above bedrock is developed to represent soil type, boundaries, shear-wave velocity (Vs), bulk density, intrinsic shear-wave damping or attenuation (Qs), and dynamic soil properties (usually representative modulus and damping versus strain curves). Commonly, this soil profile information is input into a soil-response program (often SHAKE - see Idriss and Sun, 1992), and a single site-amplification factor calculated. To account for variability and uncertainty in this information, the state-of-practice approach, such as used in Toro and Silva (2001), may randomly sample profiles from the ranges of soil boundaries, Vs, and dynamic soil properties, calculate the corresponding soil response, and from these, estimate a median site-amplification. This then is applied to the probabilistic ground motion estimated for hard-rock conditions. The state-of-the-art fully probabilistic approach (Silva, 2000, personal communication; McGuire et al., 2001; Cramer, 2003), employed in generating the Memphis seismic hazard maps, accounts for the effects of local geology by making the ground-motion attenuation relations site specific. These also are derived from distributions of possible amplifications at a particular site, but prior to doing the probabilistic calculations. We combine the site-amplification distributions with bedrock ground-motion attenuation relations to obtain site-specific attenuation relations, which then are used in the probabilistic calculations for that site (see below).

In addition to probabilistic maps that include the effect of site geology, we also have generated scenario maps for the six-quadrangle study area. These maps were generated using the deterministic program hazDXv3.f (provided by Art Frankel), modified to apply the median site amplification to median hard-rock ground-motion attenuation relations. Thus, the scenario maps represent the median ground motion expected for the given scenario earthquake, which are the ground motions one expects will be exceeded 50 percent of the time when that scenario earthquake occurs.

The Memphis probabilistic seismic hazard maps display the hazard for 2, 5, and 10 percent probabilities of exceedance in 50 years and characterize the ground shaking in terms of the maximum or peak acceleration (PGA) and the spectral acceleration (Sa) at 0.2 second and 1.0 second periods. For each scenario earthquake, scenario ground- 
motion maps are also generated at these same periods. Although displayed as smooth color contours, the hazard is calculated on a grid with spacing sufficiently fine for major geologic detail to be apparent (every 0.01 degree or about every kilometer). For each grid point, the basic idea is to derive site-specific probabilistic or scenario hazard estimates. For the probabilistic maps, we used the same range of earthquake source models and magnitude- and distance-dependent ground-motion attenuation functions used to calculate the national seismic hazard maps. The scenario maps also use these same ground-motion attenuation functions. In order to add the effects of local geology, the attenuation functions, in essence, have to become site specific at each grid point. This is accomplished by developing a distribution of amplification factors at each grid point that represents the range of possibilities at that particular site. The purpose of this document is to describe how these distributions are derived, what their major sources of uncertainty are, and how they are used to estimate the probabilistic and scenario seismic hazard maps (ground motions). We first summarize the information used to characterize the geology local to each site. We then describe our procedure for deriving the associated distribution of amplification functions and how they are used to estimate the probabilistic seismic hazard. Next, we summarize the most significant features of the Memphis, Shelby County maps (both probabilistic and scenario) and how they differ from the national seismic hazard maps. Finally, we discuss the sources of uncertainty in the site amplifications and hazard maps.

\section{Characterizing the Shallow Geology}

The physical property that controls site amplification most significantly is the shear-wave velocity (Vs) of the sediments and rocks, at least until the motions become so large that they begin to respond non-linearly (that is, an increase in shaking-levels input to the base of the sediments does not produce a proportional increase in surface motions). Unfortunately, Vs measurements did not exist for Memphis, Shelby County, prior to this project and, although we made many tens of new Vs measurements (Gomberg and others, 2003), they are still too sparsely spaced to provide the needed resolution. Thus, we derived and employed a model of the sediment layering throughout the area based on hundreds of well and engineering logs in order to estimate Vs, its uncertainties, and variations throughout Memphis, Shelby County (see below and Gomberg and others, 2003). In short, we used the more densely sampled geologic structure as a guide to extrapolate from sparsely measured Vs profiles. In addition to Vs information, calculation of site-amplification functions requires knowledge of density, water content, attenuation, and dynamic soil properties.

We built a three-dimensional model of the sediment layering beneath Memphis from interpretations of hundreds of well logs and engineering boring logs as well as surface geologic maps. Surficial materials (fig. 2) were classed as either wind-blown glacial deposits (loess) or river deposits (alluvium), based on new geologic maps of Memphis (Broughton and Van Arsdale, 2004; Cox, 2004; Moore and Dieh1, 2004a, 2004b; and Van Arsdale, 2004a, 2004b). The locations, surface elevations (fig. 3a), depths to the top of each lithologic layer estimated from each log by a geologist (fig. 3b), and other information obtained for nearly 1200 shallow (to 500 meter depth) logs have been compiled in a database maintained by the Ground Water Institute at The University of Memphis (http://gwidc.memphis.edu/website/introduction). Deeper layer boundary 
depths (the top of the Cretaceous sediments and Paleozoic limestones, fig. 4) are based on data described in Van Arsdale and TenBrink (2000). Although the constraints on the two deeper boundaries are sparse, they are sufficient to provide a regional trend within Shelby County.

To extrapolate the layer boundary depths estimated from the well and deeper data to a uniform grid, we fit surfaces to each boundary by using a moving least-squares algorithm (Gomberg and others, 2003). At each grid point, this algorithm locally fits a polynomial surface to the observations within a radius of about 100 meters $(\mathrm{m})$ from the point. Uncertainties associated with natural variability and measurement error are estimated as a weighted root-mean-square difference between modeled and observed boundary depths, and uncertainties that describe the stability of the fit surface are derived using a bootstrap resampling method (Gomberg and others, 2003). Both uncertainties are used to derive the site-amplification distributions and the correlations between lithology and Vs.

For the uppermost $100 \mathrm{~m}$, we then derived a correspondence between geologic layer material and Vs by using 76 measured Vs profiles and the modeled sedimentary structures beneath each corresponding measurement site. These correlations can be found in Gomberg and others (2003). Shear-wave velocity estimates for greater depths were made by using logs from a 420-m Memphis Light, Gas, and Water (MLGW) water well (fig. 5) and the 900-m Wilson 2 oil and gas exploration well (fig. 6). Both S-wave and Pwave velocities were logged in the MLGW well but only P-wave velocities (Vp) in the Wilson 2 well. To estimate Vs below $420 \mathrm{~m}$, we used the trend of Vp/Vs versus Vp from the MLGW $\log$ (which approached 2.3 with increasing Vp) with the Vp measurements in the Wilson $2 \log$. For the velocities of the Paleozoic limestones beneath the sediments, we used the measured $\mathrm{Vp}$ at the bottom of the Wilson 2 well and assumed a $\mathrm{Vp} / \mathrm{Vs}$ ratio of 1.7 .

Table 1 summarizes the remaining soil properties used in the determination of site-amplification distributions. Densities for various lithologic units were determined from six logged wells in Shelby County ranging from 130 to $800 \mathrm{~m}$ in depth. A density $\log$ from the 900-m exploration well in the Mississippi embayment also was used. Site amplification is not very sensitive to shallow Vs attenuation (Qs) of 10 or greater (damping of 0.05 or less); Qs in the region has been determined by Pujol et al. (2002) to be no less than 20 to 40 . There are no existing measurements of dynamic properties (modulus and damping) for Mississippi embayment sediments. Hence, we assumed a distribution described by the generic EPRI (1993) curves and their natural lognormal standard deviation of 0.35 .

\section{Site-Specific Amplification and Attenuation}

Amplification depends not only on the shear velocities and other material properties of the sediments but also on the amplitudes and frequency content of the ground-motion input to the base of the sediment layers. For each type (frequency content) of ground motions mapped (PGA, $0.2 \mathrm{~s} \mathrm{Sa}$, or $1.0 \mathrm{~s} \mathrm{Sa}$ ), our amplification factor distributions are represented by mean values and their standard deviations of multiplicative factors for a range of input amplitudes (fig. 7). To capture the true natural complexity of earthquake seismograms, we employ real recordings of earthquake ground 
motions as inputs to our amplification calculations. We use ground motions recorded on rock outcrops because our resulting amplification-factor distributions have to be combined with ground-motion attenuation relations (see below) that predict ground motions on rock. Specifically, we use 14 horizontal recordings from seven $\mathrm{M} \sim 7$ earthquakes (see table 2) obtained from the PEER strong motion database (http://peer.berkeley.edu/smcat/). Most of these earthquakes and many of the records used in this study also are part of the NRC CEUS database of time histories (McGuire and others, 2001). In addition, we used two synthetic M7.5 and M 8.0 records for hard rock from Atkinson and Beresnev (2002), as these are more representative of CEUS source characteristics, CEUS wave-propagation properties, and upper-bound New Madrid earthquake magnitudes than the real M7 records from outside the CEUS. As discussed in the uncertainty section below, figure 17 compares site-amplification results from the real earthquake records with those from the CEUS synthetic records.

Because soil amplification is nonlinear, it depends on both the amplitude and frequency of input ground motion. To build a distribution of site amplifications at a particular amplitude and frequency, a ground-motion record is randomly selected and scaled to the input ground-motion level. We scale (adjust the amplitude of) the real ground motions to obtain input rock ground motions at ten different shaking levels $(0.01$, $0.05,0.1,0.2,0.3,0.4,0.5,0.6,0.8$, and $1.0 \mathrm{~g})$. The scaling is done at the particular frequency of interest (PGA, $0.2 \mathrm{~s} \mathrm{Sa}$, or $1.0 \mathrm{~s} \mathrm{Sa}$ ). The scaled record then is input to a computer program that simulates the response (amount of amplification or deamplification) of the overlying sediments (see below). The properties of the sediments also are selected randomly from the suite of Vs profiles and dynamic soil properties described above. For each frequency and amplitude, this process of randomly choosing a ground-motion record and scaling it, randomly choosing a set of sediment properties, and calculating the response of these sediments to the scaled input motions is repeated 100 times. A mean and standard deviation is then derived from these 100 estimates of the amplified (or deamplified) ground motion.

An important aspect of determining site amplifications is the proper handling of the free-surface effect (which effectively increases the motions by a factor of two) because ground-motion attenuation relations predict surface ground motions. We use motions measured at the surface as proxies for motions at the bedrock-soil interface in the sediment-response calculations, so the scaled surface ground motions must be reduced by a factor of two, independent of frequency. Once the soil response has been calculated, the free surface effect must be put back in by multiplying the output motions by a factor of two, again independent of frequency. How a particular soil-response program does or does not handle the free surface must be determined and understood so that proper siteamplification distributions can be determined.

To simulate the sediment response, we use the computer program SHAKE91 (Idriss and Sun, 1992). However, to more accurately approximate nonlinear soil behavior at high-frequency ground shaking, we allow nonlinear response in the sediments only above $300 \mathrm{~m}$ depth (see comparisons below). Predictions of theoretical models and computer programs that more completely account for the underlying physics show that SHAKE91 overpredicts the attenuation of ground motions at high frequencies (fig. 8). We performed our own comparisons using the more complete programs DEEPSOIL (Hashash and Park, 2001, 2002) and TREMORKA (Bonilla, 2003, written commun.; 
Kausel and Assimaki, 2002). For the MLGW well 236 site of figure 5, figure 8 shows a comparison of the soil responses for input motions of $0.1 \mathrm{~g}$ and $0.5 \mathrm{~g}$ (surface) and common dynamic soil properties between SHAKE91, DEEPSOIL, TREMORKA, and SHAKE91 limited to linear response below $80 \mathrm{~m}, 300 \mathrm{~m}$, and $400 \mathrm{~m}$. For the $0.1 \mathrm{~g}$ input surface time series, the differences among the various programs and constraints are less than 50 percent. Differences are much greater for the $0.5 \mathrm{~g}$ input surface time series (please see the Uncertainty Section). These show that SHAKE91 overly damps the highfrequency motions if applied to the entire 1-km soil column. DEEPSOIL has a lower high-frequency response than TREMORKA. SHAKE91 limited to linear soil response below $300 \mathrm{~m}$ seems the best compromise to matching the newer soil-response codes, although it seems to consistently underestimate the amplitude response between 0.2 and $0.5 \mathrm{~s}$ ( 5 to $2 \mathrm{Hertz}$ ) in figure 8 . Unfortunately, these more complete programs are too computationally demanding to use for the map calculations.

Figure 7 shows representative site-amplification distributions for PGA, $0.2 \mathrm{~s} \mathrm{Sa}$, and $1.0 \mathrm{~s} \mathrm{Sa}$ for the Memphis study area. The site-amplification distributions are represented in figure 7 by the median and the $16^{\text {th }}$ and $84^{\text {th }}$ percentiles $(68$ percent confidence interval). Also shown are the NEHRP 1997 factors (taken from Joyner and Boore, 2000) for converting hard rock (NERHP soil class A) seismic amplitudes to those for NEHRP soil class D site conditions based on Vs30, the average shear-wave velocity for the top 30 meters of soil. Typically for Memphis at very strong ground motions ( $1.0 \mathrm{~g}$ ), PGA shows little amplification (near 1.0), $0.2 \mathrm{~s}$ Sa motions tend to be deamplified (amplification below 1.0), and $1.0 \mathrm{~s} \mathrm{Sa}$ motions are amplified by 150 to 200 percent. Because Memphis has very thick soils (about $1 \mathrm{~km}$ ), we would expect the median soil amplification to deviate from the NEHRP factors, which are based on Vs30. As shown on figure 7, this is the case. PGA and $0.2 \mathrm{~s}$ Sa have higher weak-motion $(<0.1 \mathrm{~g})$ median amplification but lower strong-motion median amplification relative to the NEHRP factors. For $1.0 \mathrm{~s} \mathrm{Sa}$, weak motion has similar (about 200 percent) median amplification as the NEHRP factors, but does not decrease as much as the NEHRP factors for stronger motions due to resonance in the thicker soils beneath Memphis. Bodin and Horton (1999) measured site periods of 4 to $5 \mathrm{~s}$ in Memphis.

The final step in estimating the ground motions combines the site-specific amplification-factor distributions with the regional attenuation relations. To calculate a site-specific seismic hazard, the ground-motion attenuation relations for rock need to be adjusted so they represent ground motions at the site being considered (Cramer, 2003). For a given frequency of ground motion, a ground-motion attenuation relation gives the distribution of possible ground motions for a specified magnitude and distance from an earthquake. Like the national maps, we employ five CEUS ground-motion attenuation relations: Atkinson and Boore (1995), Frankel and others (1996), Toro and others (1997), Campbell (2003), and Somerville and others (2001). Figure 9 shows the median groundmotion attenuation with distance for M 5, 6, and 7 earthquakes for PGA and 1.0s Sa. We have followed the USGS national hazard model and used all five relations for the largest New Madrid earthquakes (weighted $0.25,0.25,0.25,0.125$, and 0.125 , respectively), and only the first four relations for the smaller magnitude earthquakes (weighted 0.286, 0.286, 0.286, and 0.143, respectively). The Campbell and Somerville and others relations were down weighted because they were new relations and not well accepted yet (in 
2002). The Somerville and others relation is a finite-fault relation, unlike the others, and is not applicable to earthquakes below M6.

For each magnitude $(\mathrm{M})$ and distance $(\mathrm{R})$ used in a hazard calculation, the rock ground motions (Ar) are adjusted by the site-amplification cumulative distribution [P(As $\leq$ Ao I Ar)] to determine the corresponding distribution of site-specific ground motions (As) using the probability $(\mathrm{P})$ integral formula:

$$
\mathrm{P}(\text { As }>\text { Ao } \mid \mathrm{M}, \mathrm{R})=1-\int_{\mathrm{Ar}} \mathrm{P}(\mathrm{As} \leq \mathrm{Ao} \mid \mathrm{Ar}) \mathrm{P}(\mathrm{Ao}=\mathrm{Ar} \mid \mathrm{M}, \mathrm{R}) \mathrm{dAr} \text {, }
$$

where Ao is a level of ground motion that the soil ground motion is to have some probability of exceeding and $I$ is a conditional probability symbol that means given the values that follow it. $\mathrm{P}(\mathrm{Ao}=\mathrm{Ar} \mid \mathrm{M}, \mathrm{R})$ is the probability of Ao being Ar given $\mathrm{M}$ and $\mathrm{R}$, which is derived from the original hard-rock attenuation relation. An example of applying this formula is shown in figure 10. Additional details may be found in Cramer (2003). Once the ground-motion attenuation relations are adjusted, the hazard calculation proceeds using the earthquake sources modeled in the national seismic hazard maps.

\section{Hazard Maps}

Memphis probabilistic ground motion seismic hazard maps have been generated for PGA, $0.2 \mathrm{~s} \mathrm{Sa}$, and $1.0 \mathrm{~s} \mathrm{Sa}$ for 2\%-, 5\%-, and 10\%-in-50-year probabilities of exceedance (figures 11 through 13). These maps have been smoothed by averaging over four grid-points $(\sim 4 \mathrm{~km})$ and reassigning that average to the coordinate center of the four grid-points to remove spatial variability on the order of $0.05 \mathrm{~g}$ or less. In other words, the smoothed grid values are offset by one-half grid unit in latitude and longitude from the original grid used to estimate seismic hazard. When compared to the 2002 USGS national seismic hazard maps, the Memphis hazard maps have similar ground-motion levels for PGA, 0-30 percent lower levels for $0.2 \mathrm{~s} \mathrm{Sa}$, and about 100 percent higher levels for $1.0 \mathrm{~s} \mathrm{Sa}$. Note that the national map calculations assume a uniform geologic structure. Soil classification is dominated by the National Earthquake Hazard Reduction Program's (NEHRP) classification scheme, which is based on the average shear-wave velocity over the uppermost $30 \mathrm{~m}$. The national seismic hazard maps correspond to the $\mathrm{B} / \mathrm{C}$ boundary soil class (average S-velocity of $760 \mathrm{~m} / \mathrm{s}$ over the top $30 \mathrm{~m}$ of soil), and this site class has higher earthquake ground motions than ground motions on rock outcrops (NEHRP soil class A). All of Memphis falls entirely within NEHRP soil category $\mathrm{D}$, and the sediments thicken westward. This causes westward decreasing amplification and even deamplification of the strongest ground motions at high frequencies. Thus the 2\%- and 5\%-in-50-year PGA and $0.2 \mathrm{~s} \mathrm{Sa}$ maps (figures 11 and 12) show a decrease or flattening of the ground-motion gradient across the study area relative to the motions in the national seismic hazard maps. The largest earthquake sources are located to the northwest of Memphis. Memphis ground motions are amplified at lower frequencies, as shown by $1.0 \mathrm{~s}$ Sa maps, due to the presence of the thick sediments and limited nonlinear response at this period. We summarize the average ground-motion levels for each map in table 3.

Two scenarios with the effects of site geology also have been generated for PGA, $0.2 \mathrm{~s} \mathrm{Sa}$, and $1.0 \mathrm{~s} \mathrm{Sa}$ (figures 14 and 15). These scenario maps are for median ground motions using the same five ground-motion attenuation relations and weights as the national maps (see last paragraph of the preceding section), and also have been smoothed in the same manner as the probabilistic maps. The first scenario (figure 14) is for a M7.7 
earthquake on the southwesterly trending line of seismicity of the New Madrid seismic zone. For comparison, these scenarios are also shown with the equivalent scenario maps for the $\mathrm{B} / \mathrm{C}$ boundary soil conditions of the national maps, just as the probabilistic maps in figures 11 through 13. The general trend of the M7.7 scenario ground motions relative to the $\mathrm{B} / \mathrm{C}$ boundary maps is similar to that of the probabilistic maps discussed above. Relative to the national maps, the M7.7 scenario PGA ground motions show some amplification except in a portion of the northwest corner, and for the $1.0 \mathrm{~s}$ Sa ground motions are amplified by about 200 percent. For $0.2 \mathrm{~s} \mathrm{Sa}$, the M7.7 scenario map shows some deamplification.

The second scenario (fig. 15) is for a M6.2 earthquake at Marked Tree, Arkansas, at the southern end of the southwest-trending arm of seismicity of the New Madrid seismic zone. This scenario represents the 1843 Marked Tree earthquake and uses the Bakun and Hopper (2004) estimate for the magnitude of 6.2. Like the M7.7 scenario maps, the M6.2 scenario maps are for median ground motions and are compared with the equivalent $\mathrm{B} / \mathrm{C}$ boundary maps. Clearly, the median ground motions are small enough for the M6.2 scenario that nonlinear soil behavior is not significant. The effect of the sediments is to increase the ground motions by as much as a factor of two over those of the B/C boundary soil conditions for all three periods (PGA, $0.2 \mathrm{~s} \mathrm{Sa}$, and $1.0 \mathrm{~s} \mathrm{Sa}$ ).

Table 4 summarizes the ground-motion levels for each scenario map in a manner similar to table 3 for the probabilistic maps. Notice that the M7.7 scenario ground motions (average and range) in table 4 are almost identical to those for the 5\%-in-50-year exceedance maps in table 3 . This also is seen in comparing figure 14 with the $5 \%$-in-50year maps of figures 11 through 13. This is a consequence of the probabilistic seismic hazard estimation process and the characteristic M 7.7 New Madrid earthquakes having a 500-year mean recurrence interval (Wang and others, 2003) and represents a link between probabilistic and scenario ground-motion estimates (Frankel, 2004). This may provide some insight for building codes and structural design in Memphis. If this scenario earthquake were to occur, these results imply that a 10\%-in-50-year exceedance ground motion probabilistic hazard value may be exceeded in an 1811-1812-magnitude earthquake on the southwest arm of the New Madrid seismic zone. This could lead to disastrous consequences similar to those that occurred in the 1988 Armenia earthquake (Wyllie and Filson, 1989).

\section{Uncertainty}

Probabilistic and scenario maps have uncertainties associated with them. Cramer (2001a, 2001b) and Cramer and others (2002) indicate that probabilistic estimates can have uncertainties on the order of 50 percent, mainly due to the knowledge uncertainty as to where future large ruptures will occur, in the choice of ground-motion attenuation relation, and in the magnitude and recurrence interval of the New Madrid characteristic earthquakes. Similar uncertainties apply to scenario estimates, with the exception of recurrence interval because the earthquake is assumed to occur.

We have conducted an uncertainty and sensitivity analysis for the siteamplification distributions generated for Memphis. Overall uncertainty has been estimated using the observed variability in input ground motions (time series), soil profiles (velocity, layer boundaries, and top layer lithology), and dynamic soil properties. The Monte Carlo randomization procedure used in generating the site-amplification 
distributions provides an estimate of uncertainty. We examine the sensitivity to a specific parameter by fixing the Monte Carlo choices for all other parameters. Sensitivity then is determined from analyzing the statistics of 100 Monte Carlo simulations for the parameter of interest.

Figure 16 shows some representative PGA, $0.2 \mathrm{~s} \mathrm{Sa}$, and $1.0 \mathrm{~s}$ Sa overall uncertainty and sensitivity analysis results for the MLGW well site, which differs from the site used in figure 7 located at the northeast corner of the study area. There are small offsets among the various individual-parameter median site-amplifications from the overall median site-amplification due to the choice for the parameters that are held fixed in the sensitivity analysis. Figure 16 shows that the greatest sensitivity to parameter uncertainty is at large ground motions (greater than $0.2 \mathrm{~g}$ ), with the exception of the choice of input time series, which has a large sensitivity at all levels of ground motion. The major contributors to uncertainty are the choice of input time series, the variability observed in the soil profile, and the assumed lognormal uncertainty of 0.35 in the dynamic soil properties. The amplification appears insensitive to the choice of lithology (loess or alluvium) for the shallowest layer, which is not surprising because Gomberg and others (2003) indicate only small differences in the Vs distributions for these two soil types. Table 5 summarizes the sensitivity results.

The state-of-practice for assessing the uncertainty in site-amplification estimates is to use several (seven or more) different earthquakes. Actual records from earthquakes have more realistic phase relations (although not necessarily for the site being considered in the analysis) than synthetic time series. Synthetic time series may better match some characteristics of local earthquake records than actual records imported from other regions. In this study, we have used a mixture of 14 actual and 2 synthetic time series recorded at or generated for rock site-conditions (table 2). Figure 17 presents the variability among amplifications estimated for these input time series for a fixed profile (MGLW well site) and dynamic soil conditions. For ground motions less than $0.2 \mathrm{~g}$, PGA soil response shows greater sensitivity to the choice of input time series than $0.2 \mathrm{~s}$ and $1.0 \mathrm{~s}$ Sa soil response. Site amplification roughly correlates inversely with the magnitude of the earthquake associated with the input record. This is seen most strongly at $0.2 \mathrm{~s} \mathrm{Sa}$ and at strong input ground motions. This may be due to the effect of increasing duration of strong ground motion with increasing magnitude. Longer duration strong ground motion tends to allow nonlinear effects to occur more readily, which lowers site amplification at higher frequencies and generates the observed inverse correlation between magnitude and site amplification.

We also examined the sensitivity of site amplification to individual layer velocities and boundaries using parameters corresponding to the MLGW well site. Figure 18 shows the median and variability due to each layer's uncertainty in Vs (when the other layer Vs values are held fixed at their mean values). Clearly, the site amplification is sensitive to uncertainties in Vs for the first five layers (to $300 \mathrm{~m}$ ) and most sensitive to layers 1 through 3 (to $82 \mathrm{~m}$ ). Figure 19 presents the sensitivity results for the uncertainties in the depths to top of each layer. Interestingly, for weak ground motions (less than $0.1 \mathrm{~g}$ ), amplifications are most sensitive to uncertainties in the depth to the top of basement (hard rock), and to a somewhat lesser extent to layer 2 depths for 0.2 $\mathrm{s} \mathrm{Sa}$. At stronger ground motions, this sensitivity shifts to layers 2 and 3 for PGA and 0.2 $\mathrm{s} \mathrm{Sa}$ and layer 2 for $1.0 \mathrm{~s} \mathrm{Sa}$. However, these sensitivities are much smaller then those 
arising from the uncertainties in Vs, and the latter drive the amplification variability in figure 16.

Uncertainty in site amplification also arises from uncertainties in site-specific dynamic soil properties, the choice of computer program used to calculate site response, and our inability to model dynamic pore-pressure effects (fig. 20). In this study, a lognormal (base e) standard deviation of 0.35 (EPRI, 1993) is used to represent our ignorance of local dynamic soil properties (see fig. 16). Expert opinion (EPRI, 1993) suggests that this is a reasonable assumption. This uncertainty leads to estimated amplifications that vary from 10 to 100 percent for weak to strong ground motion, respectively. Although uncertainties have not been quantified, preliminary work shows that the median site response predicted by different programs may differ by about $\pm 50 \%$ for the same set of input parameters. Modeling of dynamic pore-pressure effects on site amplification was not feasible for this study and is a focus of research so that it may be included in the future. As figure 20 shows, this important effect also can contribute significantly to site amplification and ground-motion estimates.

\section{Summary}

State-of-the-art seismic hazard maps that include the effects of local geology have been produced for six 1;24,000 quadrangles in the Memphis area. The hazard maps are based on the national seismic hazard model and methodology, a three-dimensional lithology model derived from hundreds of well logs, geotechnical borings, and surface geophysical measurements, and empirical correlations between lithology and shear-wave velocity, Vs. Site amplification distributions, in the form of medians and natural logarithmic 16th and 84th percentile estimates (68 percent confidence limits), were derived from the lithology model and its correlation with Vs at each point of a 1-km grid. The site-amplification distributions were used to modify CEUS hard-rock ground-motion attenuation relations to obtain site-specific relations prior to calculating the hazard at each grid point.

Our products include probabilistic seismic hazard maps with the effects of local geology for 2\%-, 5\%-, and 10\%-in-50-year probability of exceedance for peak ground acceleration (PGA) and $0.2 \mathrm{~s}$ and $1.0 \mathrm{~s}$ spectral acceleration (Sa). Compared with the national seismic hazard maps, which are calculated for a constant NEHRP B/C boundary soil conditions $(760 \mathrm{~m} / \mathrm{s}$ Vs30), the Memphis seismic hazard maps show similar levels of expected ground motion for PGA, up to 30 percent reductions in expected ground motions for $0.2 \mathrm{~s} \mathrm{Sa}$, and twice the level of expected ground motions for $1.0 \mathrm{~s} \mathrm{Sa}$. At short periods (PGA and $0.2 \mathrm{~s} \mathrm{Sa}$ ), the strong gradient in probabilistic ground motions of the national maps is flattened to nearly uniform ground motions across Memphis due to the effects of the local geology.

We also provide two scenario maps with the effects of local geology for PGA, 0.2 $\mathrm{s} \mathrm{Sa}$, and $1.0 \mathrm{~s} \mathrm{Sa}$. They present median expected ground motions across Memphis from a M7.7 earthquake on a fault coinciding with the southwestern line of seismicity in the New Madrid seismic zone and a M6.2 earthquake at the southern end this linear zone of seismicity, near Marked Tree, Arkansas. The M7.7 scenario indicates average expected ground motions in Memphis of 0.35, 0.5, and $0.4 \mathrm{~g}$ for PGA, $0.2 \mathrm{~s} \mathrm{Sa}$, and $1.0 \mathrm{~s} \mathrm{Sa}$, respectively. For the M6.2 scenario, these average values are $0.1,0.2$, and $0.1 \mathrm{~g}$. Due to the nature of probabilistic and scenario hazard calculations, the M7.7 scenario maps are 
very similar to the 5\%-in-50-year probability of exceedance hazard maps, which is what is expected from the 500-year mean recurrence interval of the 1811-1812 magnitude earthquakes on the New Madrid seismic zone. This suggests that 10\%-in-50-year ground motions currently used for building design in Memphis may underestimate ground motions from a repeat of the 1811-1812 earthquakes.

We have performed uncertainty analyses for the ground-motion maps and the siteamplification distributions. Without the inclusion of the effects of local geology, the probabilistic seismic hazard estimates have been shown to have an uncertainty of plus or minus 50 percent for Memphis due to knowledge uncertainty in rupture location, magnitude, recurrence interval, and ground-motion attenuation. The major sources of uncertainty in the site-amplification estimates arise from the uncertainties in input motions, soil profile, and dynamic soil properties, which provide an overall coefficient of variation (standard deviation divided by the mean) of 10 to 60 percent. Additionally, the choice of soil-response computer program used to calculate the site-amplification distributions leads to uncertainties in the range of plus or minus 50 percent.

In light of the large uncertainties, which apply to both the probabilistic and scenario estimates, why should we have any confidence in the results of this or any other such study? It would be easy, but simplistic, to discount any and all results of such studies as this one. The power of a statistical approach comes to the fore in addressing this concern. Probabilistic approaches can incorporate knowledge variability and uncertainty into the results. Both in probabilistic and scenario estimates, the focus is on deriving a 'best' estimate of expected ground motion, which statistically corresponds to the expected (mean) value. Most importantly, use of the concept of expected value avoids extreme and worst-case estimates, which are very unlikely to occur. Thus, we do not have to fear uncertainty. With probabilistic estimates, an acceptable level of risk can be chosen both in economic and societal terms (Leyendecker and others, 2000). This choice of risk level, combined with a best estimate of the ground-motion hazard, provides a rational basis for setting public policies.

The maps presented herein represent our best estimate of the groundmotion hazard for Memphis. (We leave the choice of risk level and policy setting to others.) The Memphis hazard maps incorporate state-of-the-art science, our current understanding, and our knowledge of both what we know and what we do not know. Future improvements in our knowledge and understanding certainly will improve our estimates and reduce the overall uncertainty. We conclude on a cautionary note, emphasizing that the Memphis maps are regional in nature and not site specific. They should not be directly used in a site-specific analysis and structural design, but rather only as guidance as to what generally can be expected.

\section{Acknowledgments}

We thank Ken Campbell and Steve Hartzell for their helpful comments and reviews, which helped us improve this manuscript. We also thank Alene Brogan and Bob Olmstead for their editing suggestions. 


\section{References}

Atkinson , G.M., and Beresnev, I.A., 2002, Ground motions at Memphis and St. Louis from M 7.5-8.0 earthquakes in the New Madrid seismic zone, Bulletin Seismological Society of America, vol. 92, p. 1015-1024.

Atkinson, G.M. and Boore, D.M., 1995, Ground motion relations for eastern North America, Bulletin Seismological Society of America, vol. 85, p. 17-30.

Bakun, W.H., and Hopper, M.G, 2004, Magnitudes and locations of the 1811-1812 New Madrid, Missouri, and the 1886 Charleston, South Carolina, earthquakes, Bulletin Seismological Society of America, vol. 94, p. 64-75.

Bodin, P., and Horton, S., 1999, Broadband microtremor observation of basin resonance in the Mississippi embayment, central US, Geophysical Research Letters, vol. 26, p. 903906.

Broughton, J., and Van Arsdale, R., 2004, Geologic map of the Northwest Memphis 7.5minute quadrangle, USGS MF map, in preparation.

Campbell, K.W., 2003, Prediction of strong ground motion using the hybrid empirical method and its use in the development of ground-motion (attenuation) relations in eastern North America, Bulletin Seismological Society of America, vol. 93, p. 1012-1033.

Cox, R., 2004, Geologic map of the Ellendale 7.5-minute quadrangle, USGS MF map, in preparation.

Cramer, C.H., 2001a, The New Madrid seismic zone: capturing variability in seismic hazard analyses, Seismological Research Letters, vol. 72, p. 664-672.

Cramer, C.H., 2001b, A seismic hazard uncertainty analysis for the New Madrid seismic zone, Engineering Geology, vol. 62, p. 251-266.

Cramer, C.H., 2003, Site-specific seismic hazard analysis that is completely probabilistic, Bulletin Seismological Society of America, vol. 93, p. 1841-1846.

Cramer, C.H., Wheeler, R.L., and Mueller, C.S., 2002, Uncertainty analysis for seismic hazard in the southern Illinois basin, Seismological Research Letters, vol. 73, p. 792-805.

EPRI, 1993, Guidelines for determining design basis ground motions, Earthquake Engineering Research Institute, TR-102293.

Frankel, A., 2004, How can seismic hazard around the New Madrid seismic zone be similar to that in California?, Seismological Research Letters, vol. 75, in press. 
Frankel, A., Mueller, C., Barnhard, T., Perkins, D., Leyendecker, E.V., Dickman, N., Hanson, S., and Hopper, M., 1996, National Seismic-Hazard Maps: Documentation June 1996, U.S. Geological Survey, Open-File Report 96-532.

Frankel, A.D., Petersen, M.D., Mueller, C.S., Haller, K.M., Wheeler, R.L., Leyendecker, E.V., Wesson, R.L., Harmsen, S.C., Cramer, C.H., Perkins, D.M., and Rukstales, K.S., 2002, Documentation for the 2002 update of the national seismic hazard maps, U.S. Geological Survey, Open-File Report 02-420.

Gomberg, J., Waldron, B., Schweig, E., Hwang, H., Webbers, A., Van Arsdale, R., Tucker, K., Williams, R., Street, R., Mayne, P., Stephenson, W., Odum, J., Cramer, C., Updike, R., Hutson, S., and Bradley, M., 2003, Lithology and shear velocity in Memphis, Tennessee, Bulletin Seismological Society of America, vol. 93, p. 986-997.

Hashash, Y.M.A, and Park, D., 2001, Non-linear one-dimensional seismic ground motion propagation in the Mississippi embayment, Engineering Geology, vol. 62, p. 185-206.

Hashash, Y.M.A, and Park, D., 2002, Viscous damping formulation and high frequency motion propagation in non-linear site response analysis, Soil Dynamics and Earthquake Engineering, vol. 22, p. 611-624.

Idriss, I.M., and Sun, J.I., 1992, User's manual for SHAKE91, Center for Geotechnical Modeling, Department of Civil and Environmental Engineering, University of California, Davis, California.

Joyner, W.B., and Boore, D.M., 2000, Recent developments in earthquake ground motion estimation, Proceedings of the Sixth International Conference on Seismic Zonation, November 12-15, 2000, Palm Springs, CA, Earthquake Engineering Research Institute, Oakland, CA, 7 pp.

Kausel, E., and Assimaki, D., 2002, Seismic simulation of inelastic soils via frequencydependent moduli and damping, Journal of Engineering Mechanics, vol. 128, p. 34-47.

Kramer, S.L., 1996, Geotechnical Earthquake Engineering, Prentice Hall, Upper Saddle River, New Jersey, 653 pp.

Leyendecker, E.V., Hunt, R.J., Frankel, A.D., and Rukstales, K.S., 2000, Development of maximum considered earthquake ground motion maps, Earthquake Spectra, vol. 16, p. 21 -40 .

McGuire, R.K., Silva, W.J., and Constantino, C., 2001, Technical basis for revision of regulatory guidance on design ground motions: hazard- and risk-consistent ground motion spectra guidelines, NUREG/CR-6728, prepared for the U.S. Nuclear Regulatory Commission, Office of Nuclear Regulatory Research, Division of Engineering Technology. 
Moore, D., and Diehl, S., 2004a, Geologic map of the Southeast Memphis 7.5-minute quadrangle, USGS MF map, in preparation.

Moore, D., and Diehl, S., 2004b, Geologic map of the Southwest Memphis 7.5-minute quadrangle, USGS MF map, in preparation.

Pujol, J., Pezeshk, S., Zhang, Y., and Zhao, C., 2002, Unexpected values of Qs in the unconsolidated sediments of the Mississippi embayment, Bulletin Seismological Society of America, vol. 92, p. 1117-1128.

Somerville, P., Collins, N., Abrahamson, N., Graves, R., and Saikia, C., 2001, Ground motion attenuation relations for the central and eastern United States, Final Report to the USGS, June 30, 2001, URS Group, Inc., Pasadena, CA, 36 pp.

Toro, G., Abrahamson, N., and Schneider, J., 1997, Model of strong ground motions from earthquakes in central and eastern North America: best estimates and uncertainties, Seismological Research Letters, vol. 68, p. 41-57.

Toro, G.R., and Silva, W.J., 2001, Scenario earthquakes for Saint Louis, MO, and Memphis, TN, and seismic hazard maps for the central United States region including the effect of site conditions, Final technical report to the USGS, 10 January 2001, Rick Engineering, Inc., Boulder, Colorado.

Van Arsdale, R.B., and TenBrink, R.K., 2000, Late Cretaceous and Cenozoic geology of the New Madrid seismic zone, Bulletin Seismological Society of America, vol. 90, p. 345-356.

Van Arsdale, R., 2004a, Geologic map of the Germantown 7.5-minute quadrangle, USGS MF map, in preparation.

Van Arsdale, R., 2004b, Geologic map of the Northeast Memphis 7.5-minute quadrangle, USGS MF map, in preparation.

Wang, Z., Woolery, E.W., Shi, B., and Kiefer, J., 2003, Communicating with uncertainty: a critical issue with probabilistic seismic hazard analysis, EOS, Transactions of the American Geophysical Union, vol. 84, p. 501, 506, and 508.

Wessel, P., and Smith, W.H.F. , 1991, Fee software helps map and display data, EOS, Transactions of the American Geophysical Union, vol. 72, p. 445-446.

Wyllie, L.A., and Filson, J.R., 1989, Armenia Earthquake Reconnaissance Report, Earthquake Spectra, Special Issue, 175 pp. 
Table 1: Soil Properties used in Analysis

Formation

Alluvium

Loess

Lafayette (sand, gravel)

Upper Clairborne (clay)

Memphis Sand

Flour Island (clay)

Fort Pillow Sand

Old Breastworks (clay)

Cretaceous (clay)

Paleozoic Limestone

$\begin{array}{lcc}\begin{array}{c}\text { S-Velocity } \\ (\mathrm{m} / \mathrm{s})\end{array} & \begin{array}{c}\text { Density } \\ (\mathrm{g} / \mathrm{cc})\end{array} & \text { Qs } \\ 169+/-24 & 0.20 & 10 \\ 191+/-35 & 0.20 & 10 \\ 268+/-72 & 0.20 & 25 \\ 360+/-50 & 0.20 & 25 \\ 550+/-200 & 0.20 & 25 \\ 675+/-100 & 0.20 & 25 \\ 775+/-50 & 0.20 & 50 \\ 850+/-50 & 0.20 & 50 \\ 1175+/-125 & 0.25 & 50 \\ 3400+/-150 & 0.28 & 500\end{array}$

Table 2: M 7 Strong-Motion Time Series on Rock used in Analysis

$\begin{array}{lll}\text { Earthquake } & \text { Station } & \text { Components } \\ \text { 1989 M6.9 Loma Prieta, CA } & \text { G01 } & \text { E, N } \\ \text { 1992 M7.1 Cape Mendocino, CA } & \text { CPM } & \text { E, N } \\ \text { 1992 M7.3 Landers, CA } & \text { JOS } & \text { E, N } \\ \text { 1995 M6.9 Kobe, Japan } & \text { KJM } & \text { E, N } \\ \text { 1999 M7.4 Kocaeli, Turkey } & \text { GBZ } & \text { W } \\ & \text { IZT } & \text { S } \\ \text { 1999 M7.6 Chi Chi, Taiwan } & \text { TCU046 } & \text { N, W } \\ \text { 1999 M7.1 Duzce, Turkey } & \text { 1060 } & \text { E, N } \\ \text { Atkinson and Beresnev, 2002 } & \text { M7.5 \& M8.0 at Memphis, TN }\end{array}$

Table 3: Average Ground-Motion Values with Range (not standard deviation). PGA peak ground acceleration; $\mathrm{Sa}$ - spectral acceleration.

$\begin{array}{llll}\text { ProbabilitylMotion } & \text { PGA }(\mathrm{g}) & 0.2 \mathrm{sec} \mathrm{Sa}(\mathrm{g}) & 1.0 \mathrm{sec} \mathrm{Sa}(\mathrm{g}) \\ 2 \% \text { in 50 years } & 0.58 \pm 0.09 & 0.71 \pm 0.15 & 0.71 \pm 0.23 \\ 5 \% \text { in 50 years } & 0.38 \pm 0.07 & 0.48 \pm 0.10 & 0.36 \pm 0.12 \\ 10 \% \text { in 50 years } & 0.24 \pm 0.04 & 0.33 \pm 0.07 & 0.18 \pm 0.05\end{array}$

Table 4: Scenario Average Ground-motion Values with Range (not standard deviation). PGA - peak ground acceleration; Sa - spectral acceleration.

$\begin{array}{llll}\text { ScenariolMotion } & \text { PGA }(\mathrm{g}) & 0.2 \mathrm{sec} \mathrm{Sa}(\mathrm{g}) & 1.0 \mathrm{sec} \mathrm{Sa}(\mathrm{g}) \\ \text { M7.7 earthquake } & 0.36 \pm 0.07 & 0.48 \pm 0.10 & 0.39 \pm 0.18 \\ \text { M6.2 earthquake } & 0.13 \pm 0.07 & 0.20 \pm 0.04 & 0.08 \pm 0.05\end{array}$


Table 5: Site-amplification Sensitivity (multiplicative/divisor factors for $84^{\text {th }}$ and $16^{\text {th }}$ percentile). PGA - peak ground acceleration; $\mathrm{Sa}$ - spectral acceleration.

TypelSensitivity PGA

Overall

Input Time Series

Soil Profile

$1.2-1.7$

$1.2-1.4$

$1.07-1.2$

Dynamic Properties 1.03-1.4

Top Layer Lithology $1.003-1.018$
$0.2 \mathrm{sec} \mathrm{Sa}$

1.1-1.4

1.08-1.4

1.1-1.2

1.03-1.2

$1.007-1.08$
$1.0 \mathrm{sec} \mathrm{Sa}$

1.1-1.4

1.09-1.4

$1.1-1.2$

1.03-1.3

1.004-1.03 


\section{Figure Captions}

Figure 1: Map showing the location of the six 7.5-minute quadrangle Memphis, Tennessee, study area (box). Also shown is the outline of the Mississippi embayment (heavier lines), and the location of the MLGW water well (circle) and Wilson 2 exploration well (triangle).

Figure 2: Map of the distribution of alluvium (blue) and loess (white) in the six 7.5minute quadrangles (outlined by the blue square) of the current mapping effort. The distribution in the Collierville quadrangle east of these is shown as it will be used when the hazard map area is expanded to include Collierville (an area of rapid development in Shelby County). More complete geologic maps (ref) are available that show the distribution of all sedimentary units.

Figure 3: (a) Surface elevation data from the water wells used to define a well-top elevation map for extrapolating geology model data to a uniform grid. (b) Subsurface elevations of tops of lithologic units as interpreted from water wells. In both (a) and (b) the elevation and boundary surfaces have been contoured in GMT (Wessel and Smith, 1991). The black dots indicate the locations of the wells.

Figure 4: Estimated depths to the top of the Paleozoic limestones (top figures) and Cretaceous sediments (bottom figures). Black dots indicate locations where well log observations (from Van Arsdale and TenBrink, 2000) constrain these boundaries. Surfaces on the left are contoured in GMT (Wessel and Smith, 1991) and those on the right are estimated using the approach in Gomberg et al. (2003); the latter are used in the site-amplification calculations.

Figure 5: P-wave (red) and shear wave (blue) logs for the Memphis Light, Gas, and Water (MLGW) well (circle in fig. 1). Black horizontal lines indicate lithologic boundaries (units labeled) from a gamma-ray log for the hole.

Figure 6: P-velocity (Vp) suspension log for the Wilson 2 exploration well (triangle in fig. 1). Black horizontal lines indicate lithologic boundaries from a gamma-ray log for the hole. The high velocity excursion in the second layer is due to the steel casing installed in that shallow portion of the well.

Figure 7: Example of median site-amplification estimates (solid curves) and $16^{\text {th }}$ and $84^{\text {th }}$ percentile uncertainties (dotted curves) for a site in Memphis, assuming hard-rock beneath the sediments. Circles represent NEHRP site factors for soil class D amplification over soil class A ground motions (see text for details).

Figure 8: Response spectra comparisons for $0.1 \mathrm{~g}$ input (top) and $0.5 \mathrm{~g}$ input (bottom) at the MLGW well site (circle in fig. 1). The black spectrum is the surface response spectrum of the input ground motion. The colored spectra are surface soil-response spectra for various soil response programs and constraints: SHAKE91 unconstrained (red), DEEPSOIL (magenta), TREMORKA (green), SHAKE91 linear below $300 \mathrm{~m}$ 
(blue), SHAKE91 linear below $400 \mathrm{~m}$ (light blue), and SHAKE91 linear below $80 \mathrm{~m}$ (yellow).

Figure 9: Eastern North America ground-motion attenuation relations (for uniform NEHRP B/C boundary soil conditions) used in the USGS national and Memphis seismic hazard maps. PGA (top) and $1.0 \mathrm{~s}$ Sa (bottom) median attenuation curves for M5.0 (dashed), M6.0 (dotted), and M7.0 (solid) earthquakes predicted by the relations of Frankel et al. (1996) in red, Atkinson and Boore (1995) in blue, Toro et al. (1997) in green, Somerville et al. (2001) in light blue, and Campbell (2003) in magenta. Distance is epicentral distance and has been calculated using the assumption of a vertical strikeslip fault with a hypocentral depth of $10 \mathrm{~km}$.

Figure 10: Comparison of hard-rock PGA (squares) and soil PGA (diamonds) probability of exceedance (hazard) curves for a specific magnitude (M) and distance (R). This illustrates what happens to a hazard curve when it is transformed from a hard rock curve to a site-specific curve (from Cramer, 2003). This example is for a median ground motion of $0.85 \mathrm{~g}$ with a natural logarithmic standard deviation of 0.75 .

Figure 11: Probabilistic seismic hazard maps showing ground motions with a 2\%-in-50year probability of exceedance. Smaller maps (inset squares) for Memphis, Shelby County that include the effects of site geology (site amplification) are superimposed on the 2002 national seismic hazard maps, which are for a constant soil condition (NEHRP $\mathrm{B} / \mathrm{C}$ boundary or $760 \mathrm{~m} / \mathrm{s} \mathrm{Vs} 30$ ). As labeled, the maps are for $0.2 \mathrm{~s} \mathrm{Sa}, 1.0 \mathrm{~s} \mathrm{Sa}$, and PGA.

Figure 12: Probabilistic seismic hazard maps showing ground motions with a 5\%-in-50year probability of exceedance. Presentation is the same as in figure 11.

Figure 13: Probabilistic seismic hazard maps showing ground motions with a 10\%-in-50year probability of exceedance. Presentation is the same as in figure 11.

Figure 14: Scenario maps for a M 7.7 earthquake on a fault coincident with the southwest trending line of seismicity in the New Madrid seismic zone. The presentation is similar to that in figure 11.

Figure 15: Scenario maps for a M6.2 earthquake at the southern end of the southwest trending line of seismicity in the New Madrid seismic zone. The presentation is the same as in figure 14.

Figure 16: Overall uncertainty and major sensitivities for the MLGW well site (circle in fig. 1) for PGA, $0.2 \mathrm{~s} \mathrm{Sa}$, and $1.0 \mathrm{~s} \mathrm{Sa}$. Median amplification curves (solid lines) are shown with their corresponding $16^{\text {th }}$ and $84^{\text {th }}$ percentile uncertainties (dotted lines). Uncertainties are derived by allowing all parameters to vary (red), only the input time series (blue), only the soil profile (light blue), only the dynamic soil properties (green), and only the top-layer geology (alluvium versus loess) (magenta). 
Figure 17: Site amplification variations due to the choice of input time series presented in a manner similar to figure 16. Each curve is the site-amplification response for the indicated earthquake record as input (lower legend applies to all three panels) for a common soil profile and dynamic soil properties. These variations in site amplification lead to the input time series sensitivity shown in figure 16.

Figure 18: Individual-layer Vs sensitivity for the MLGW-well soil profile for PGA, $0.2 \mathrm{~s}$ $\mathrm{Sa}$, and $1.0 \mathrm{~s} \mathrm{Sa}$. For each period the layer sensitivities are split between two plots (1-5 on left and 6-10 on right; center legend applies to all three panels). Layers 1 and 2 are for alternative surface geology (alluvium and loess, respectively). The presentation is similar to that in figure 16.

Figure 19: Individual-layer depth-to-top sensitivity for the MLGW-well soil profile presented in a manner similar to figure 18. Soil geology is not distinguished for the top layer in this figure and the layer numbers correspond to the actual layers in the MLGW soil model ending with bedrock as layer 9 .

Figure 20: Seismograms at soft-soil sites demonstrating nonlinear soil responses that are enriched (top) and depleted (bottom) in high-frequencies. The former is of the Nisqually, WA earthquake recorded at SNS (north component) and the latter is of the Loma Prieta, CA earthquake recorded at TRI (north component). 


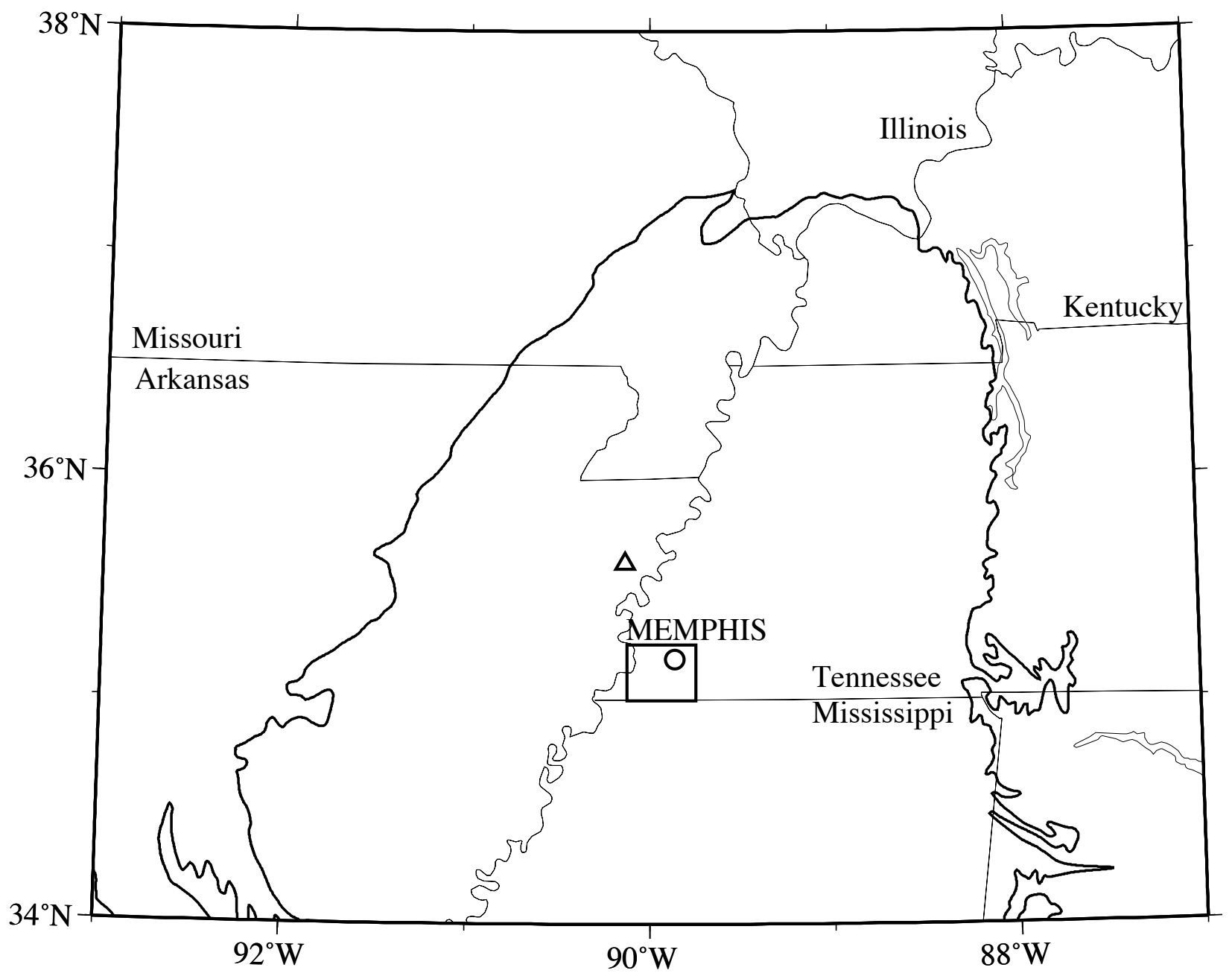

Figure 1. 


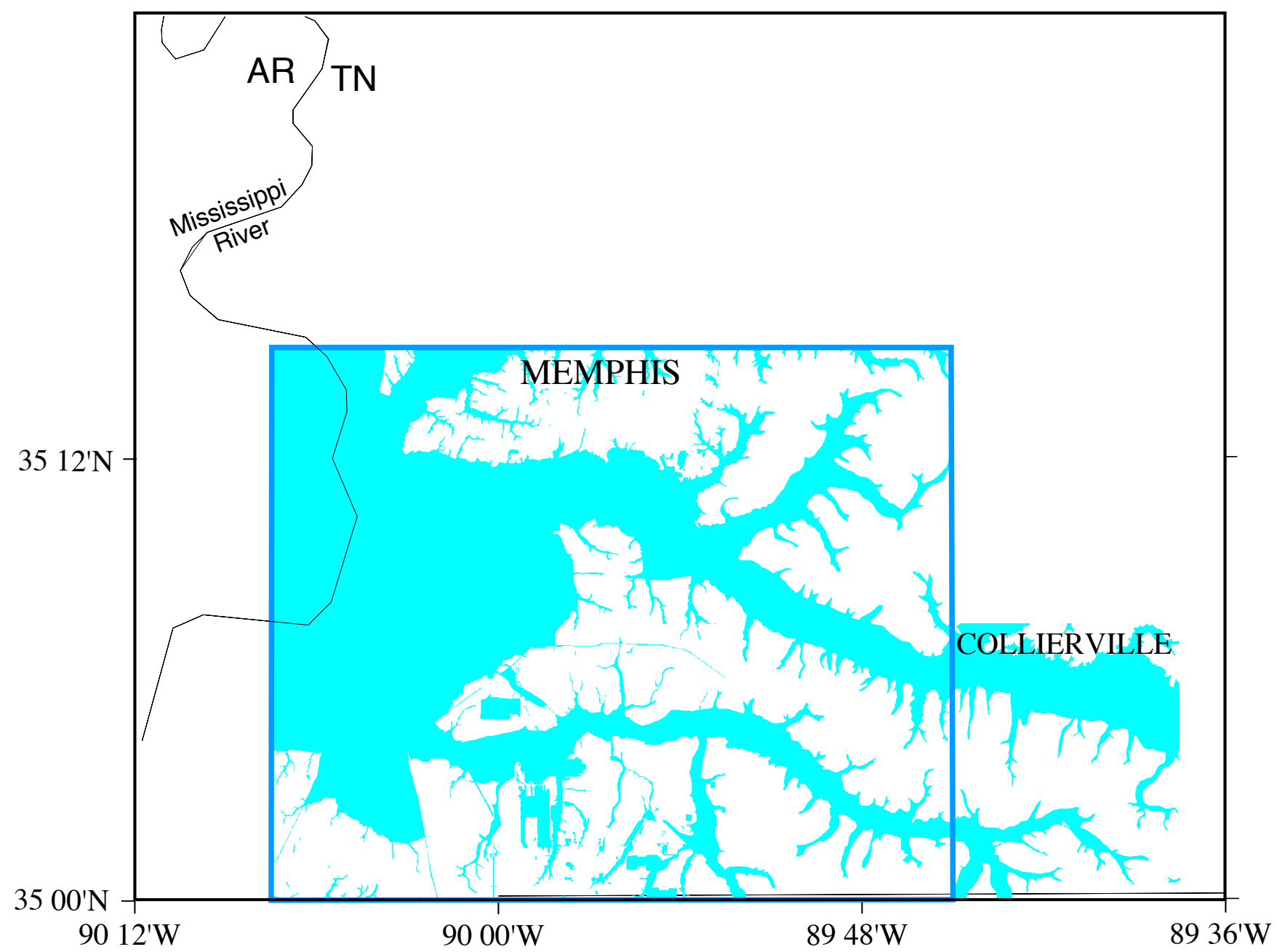

Figure 2 
(a)

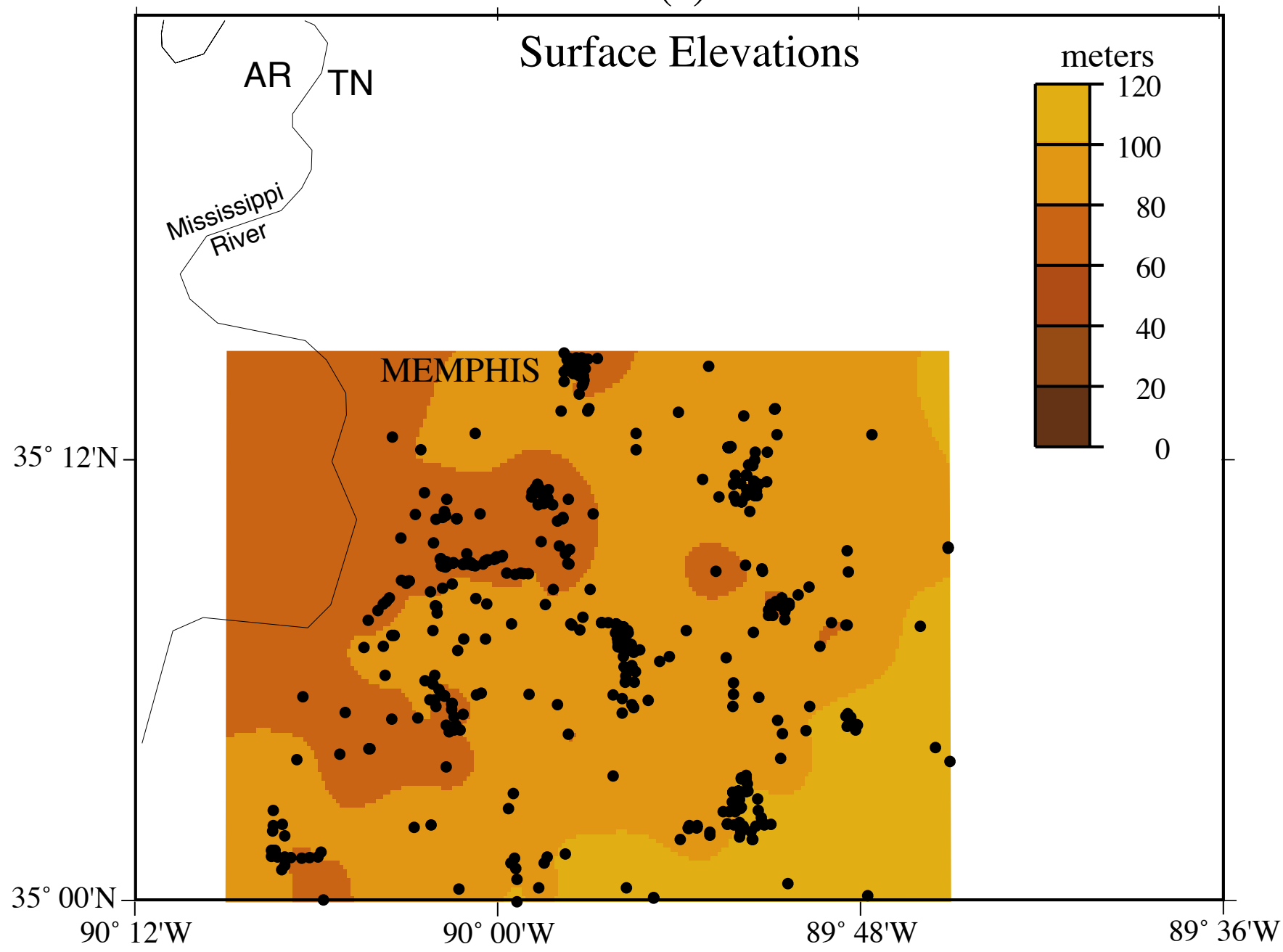

Figure 3(a) 
(b)
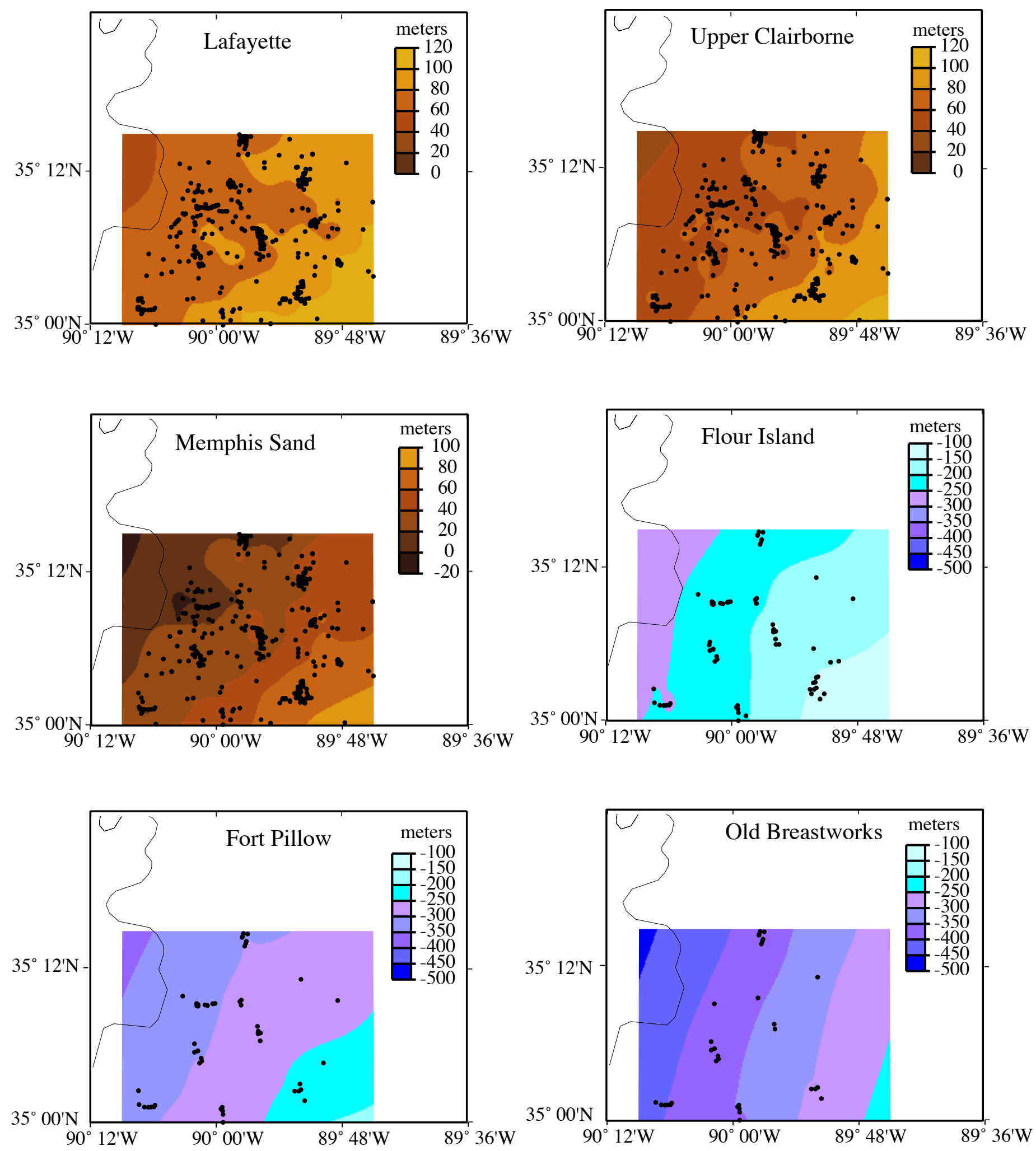

Figure 3(b) 

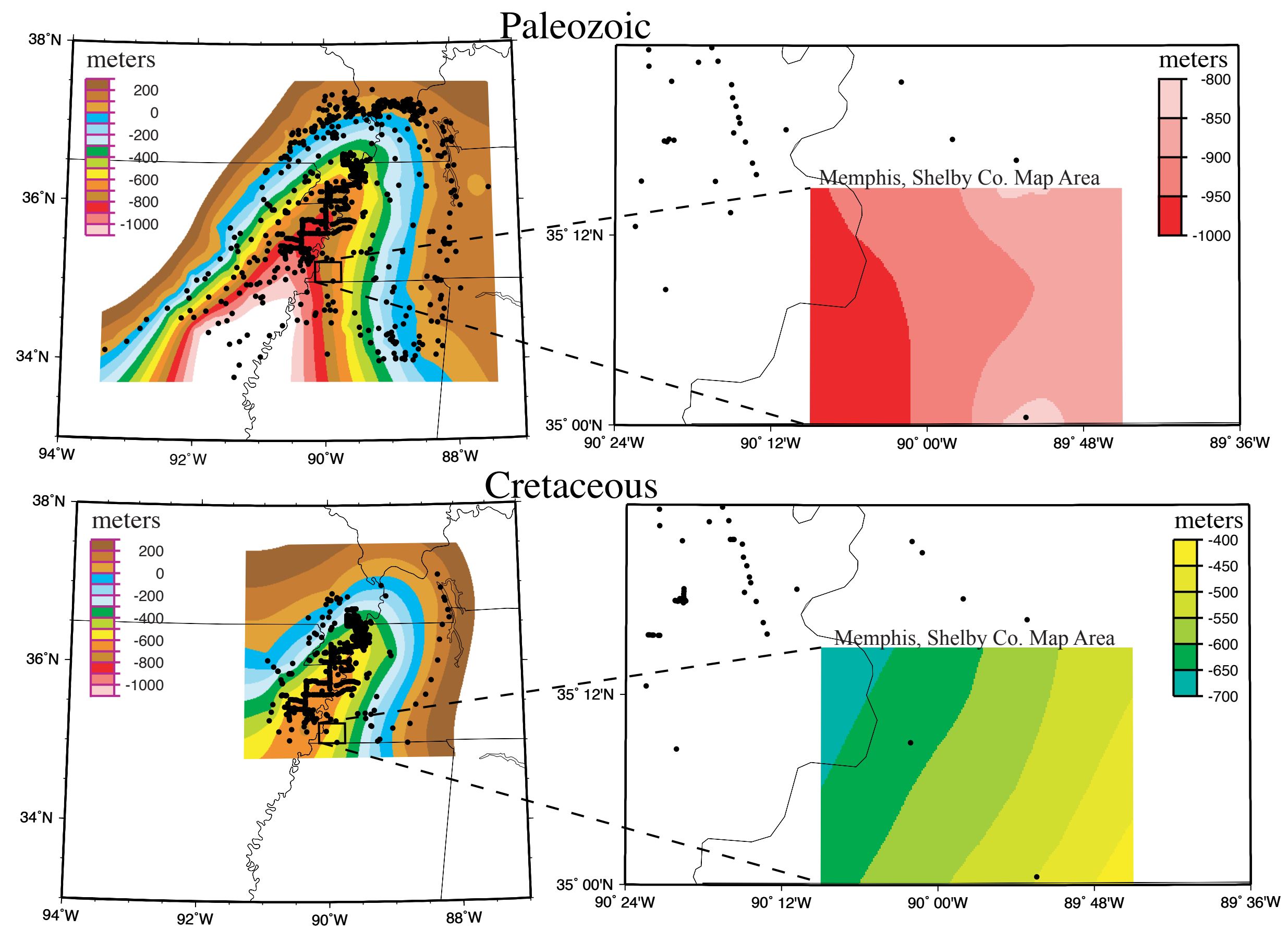


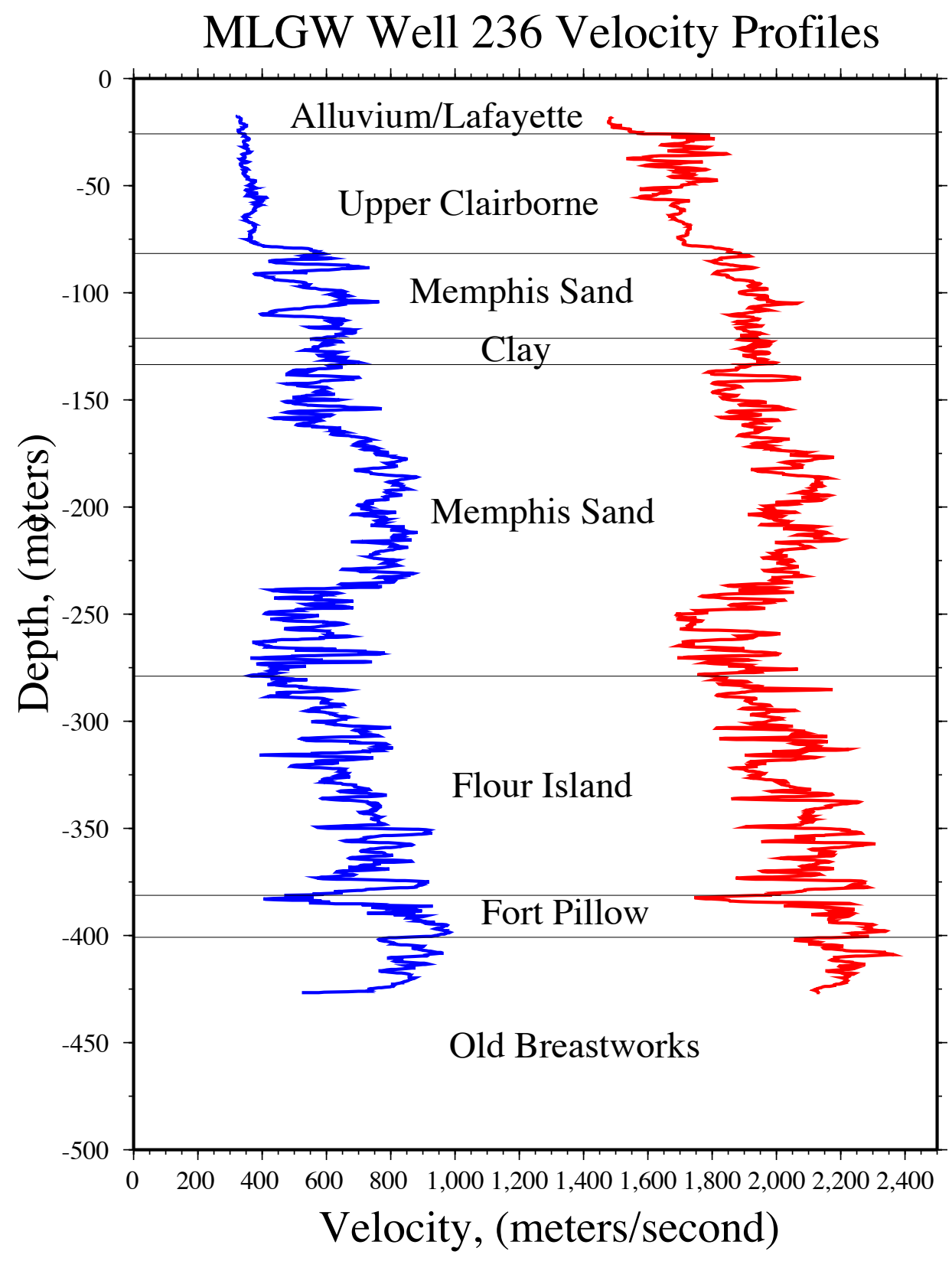

Figure 5 


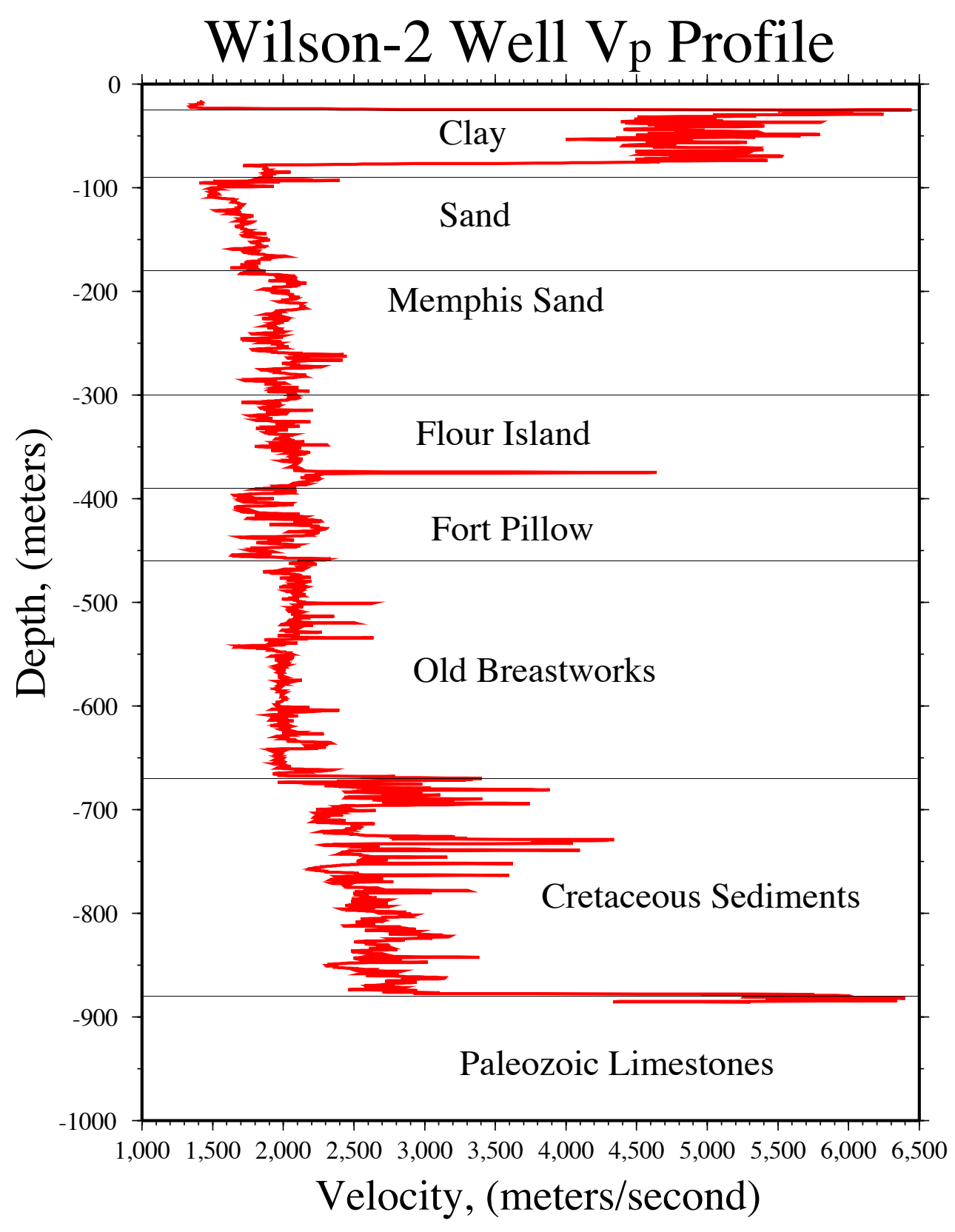

Figure 6 
Site Amplifications (Soil over Hard Rock)
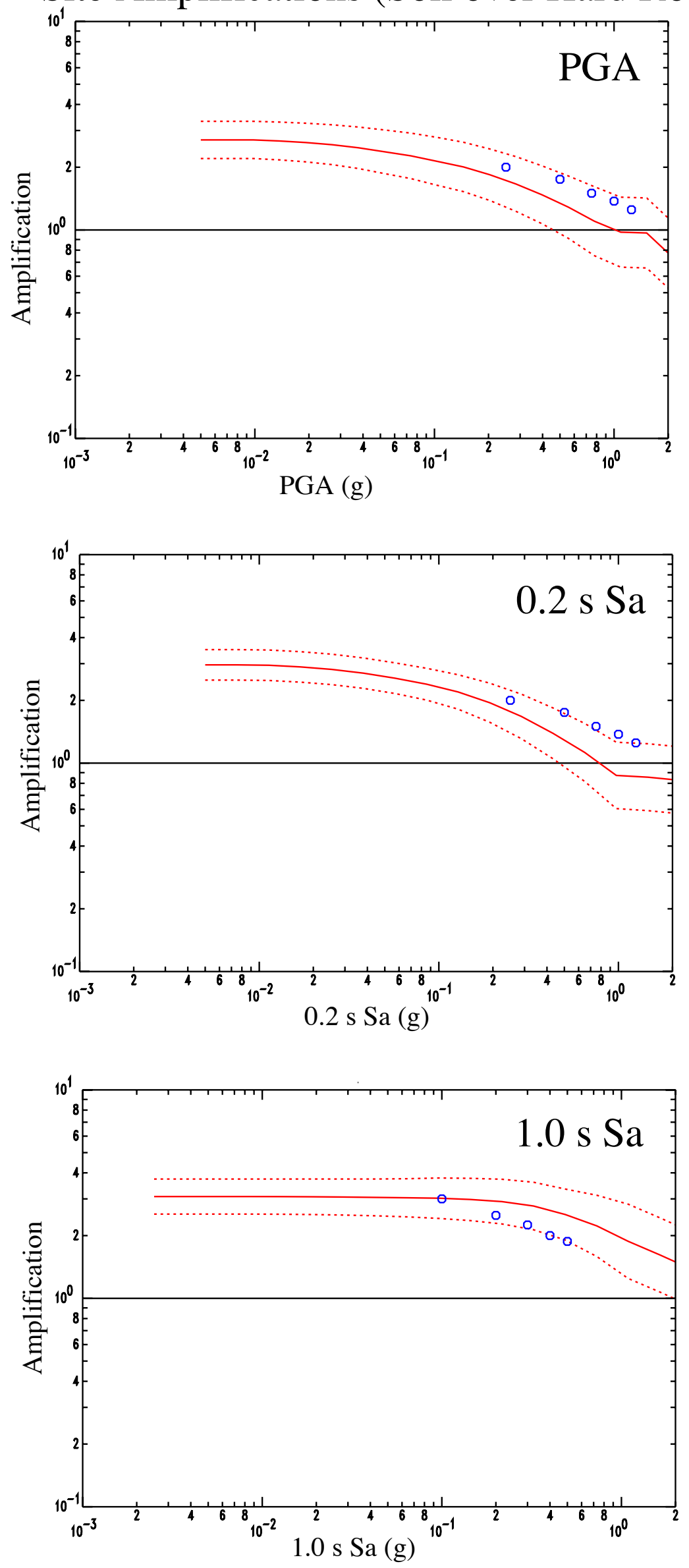

Figure 7 

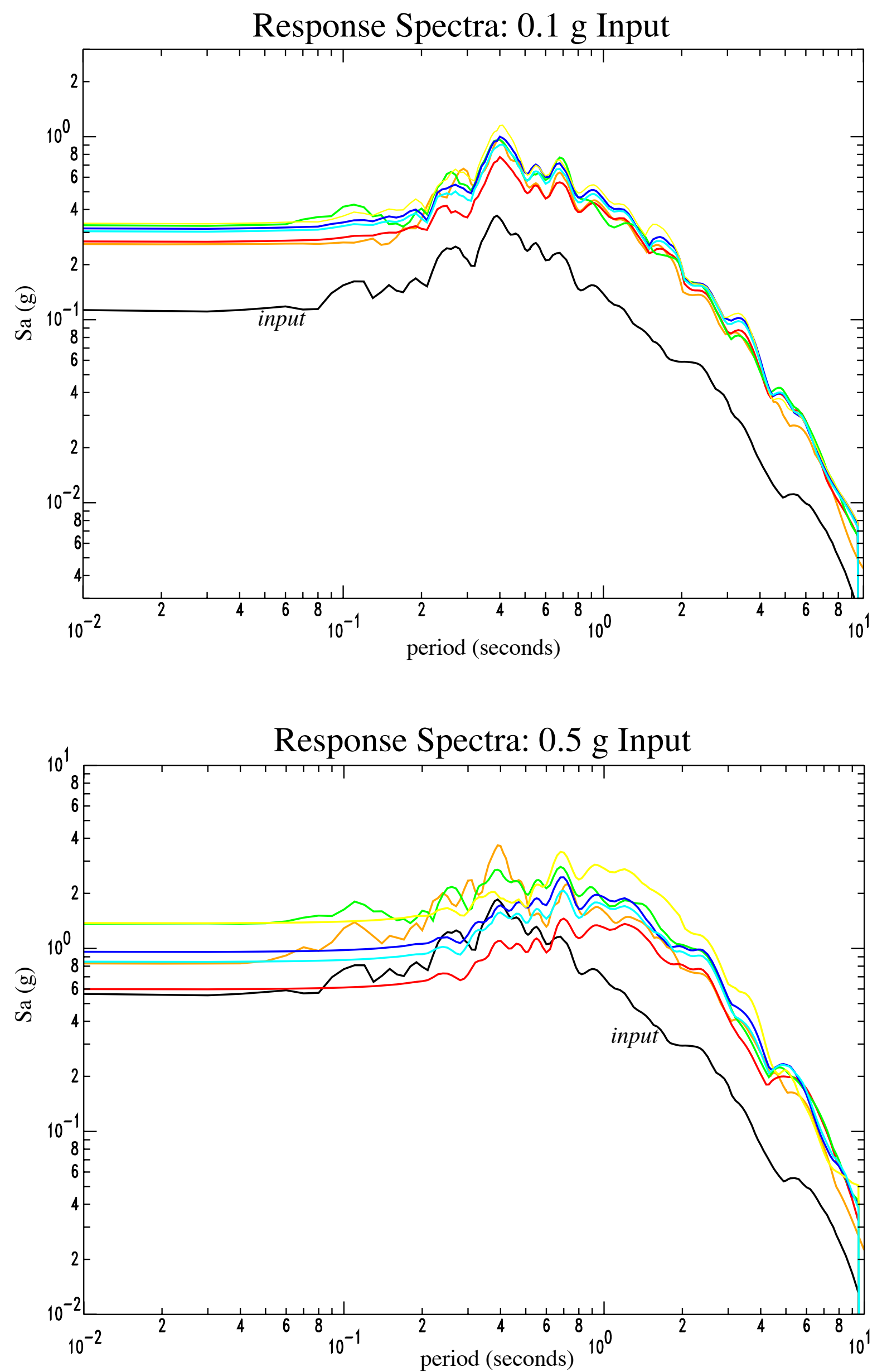

Figure 8 

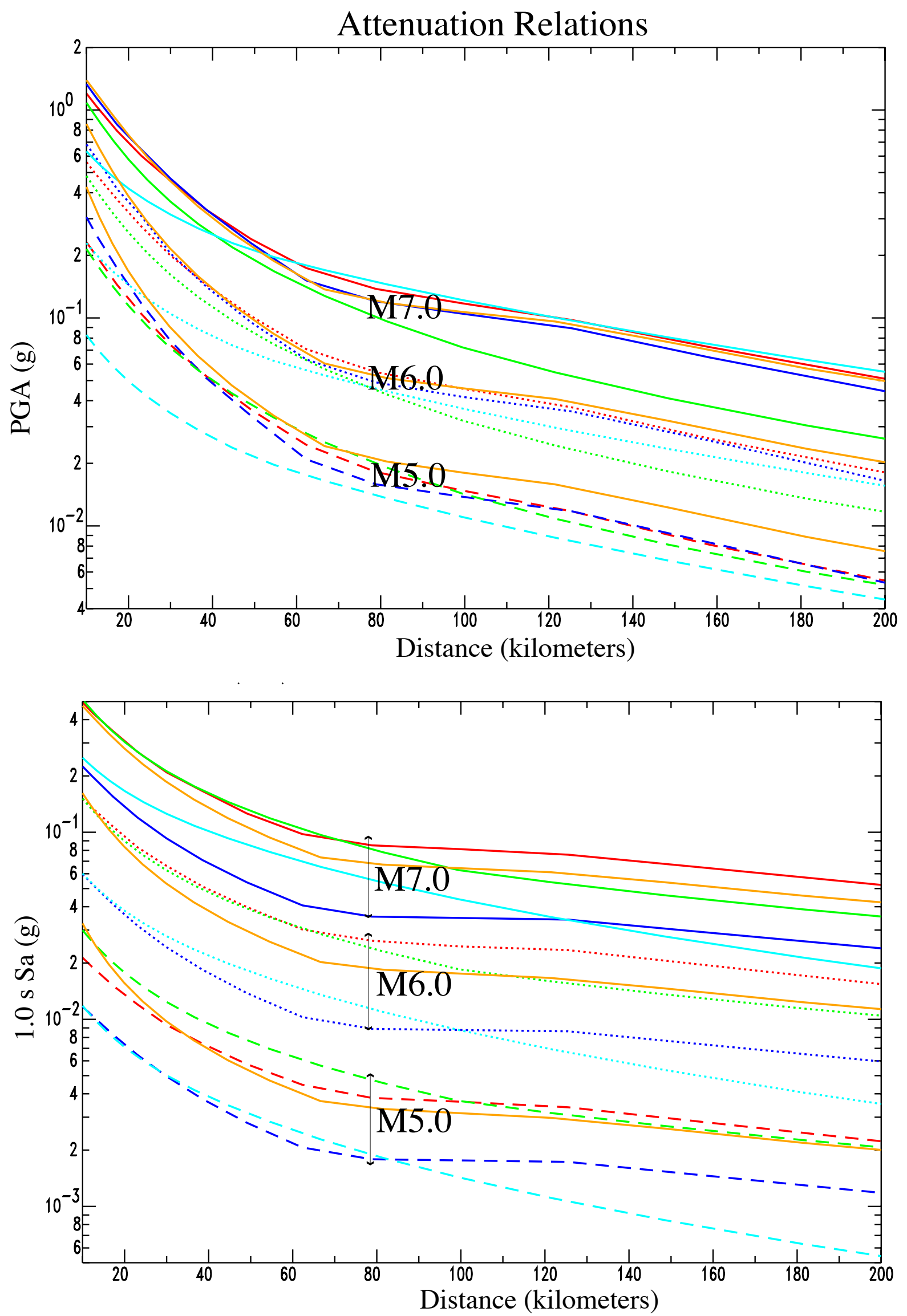

Figure 9 


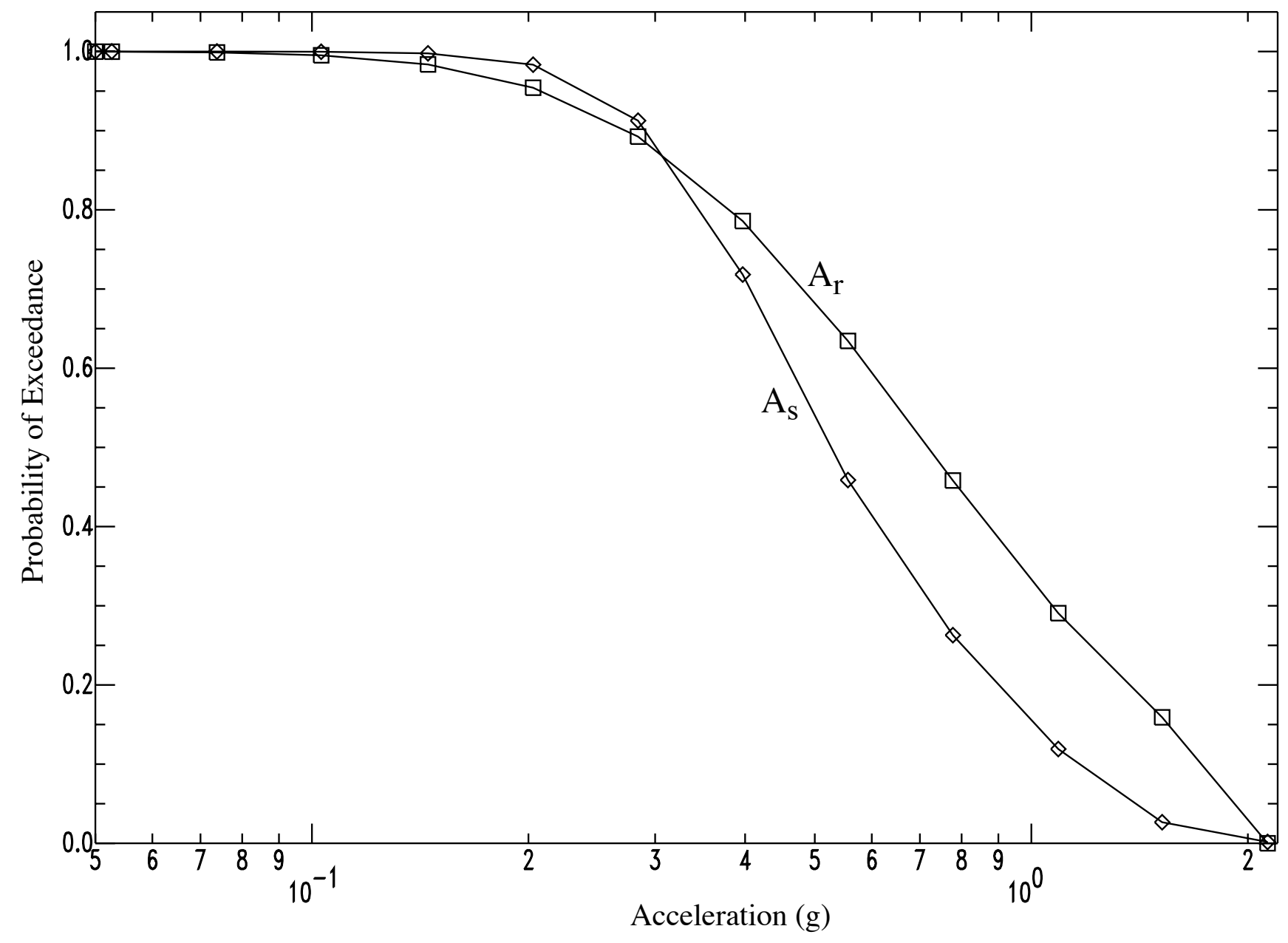

Figure 10 
Ground Motions with 2\%-in-50-Year Exceedance Probability
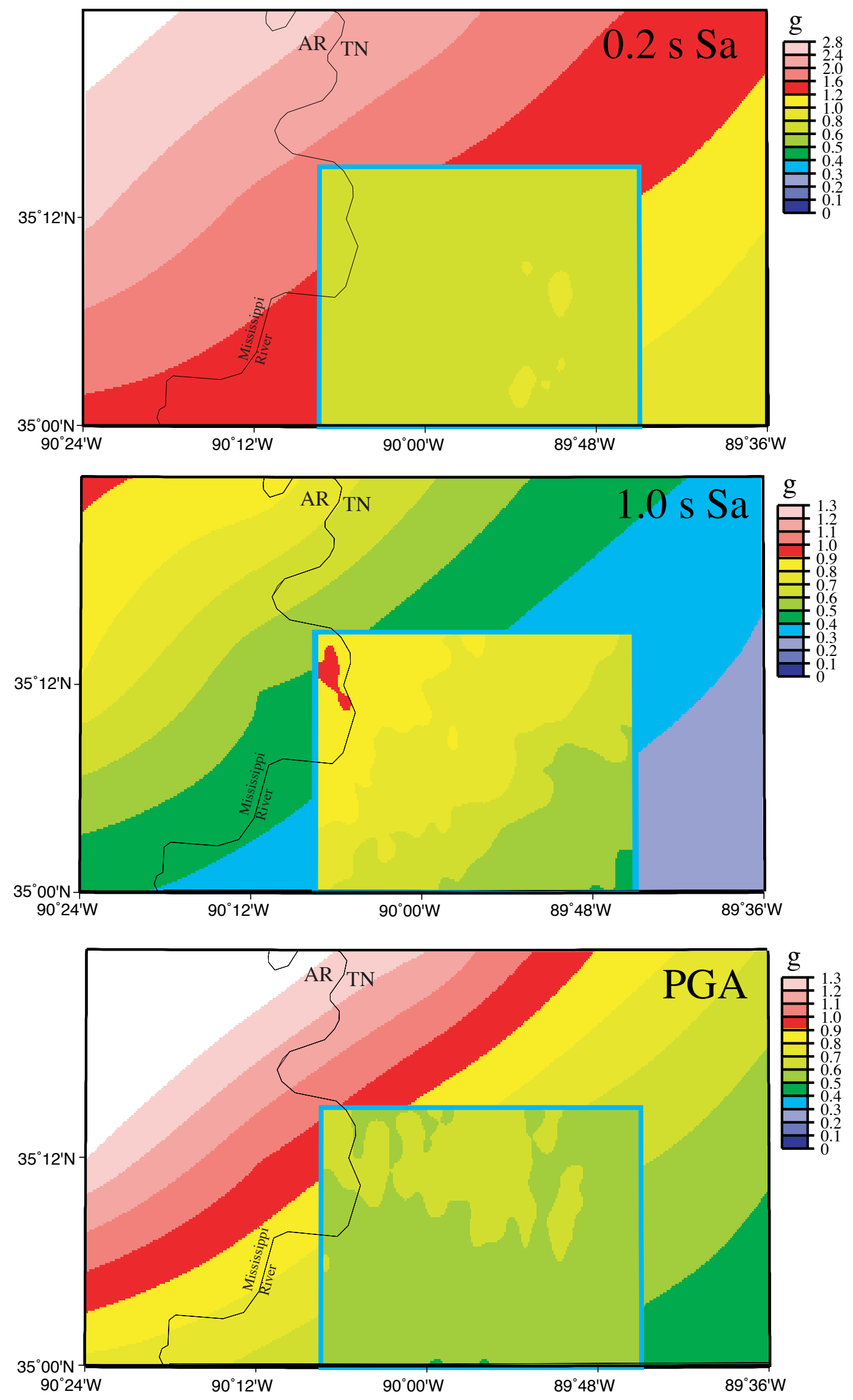

Figure 11 
Ground Motions with 5\%-in-50-Year Exceedance Probability
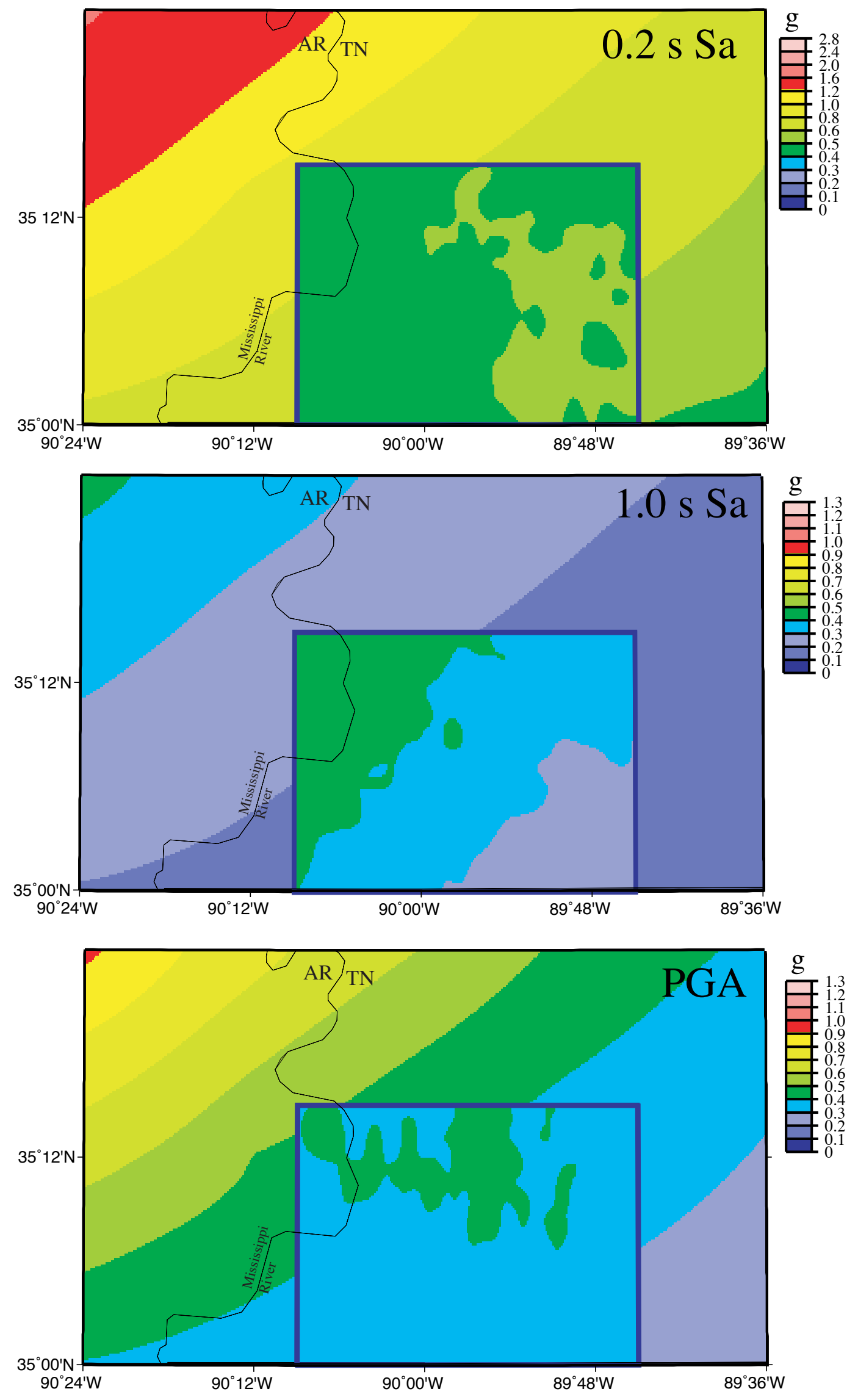

Figure 12 
Ground Motions with 10\%-in-50-Year Exceedance Probability
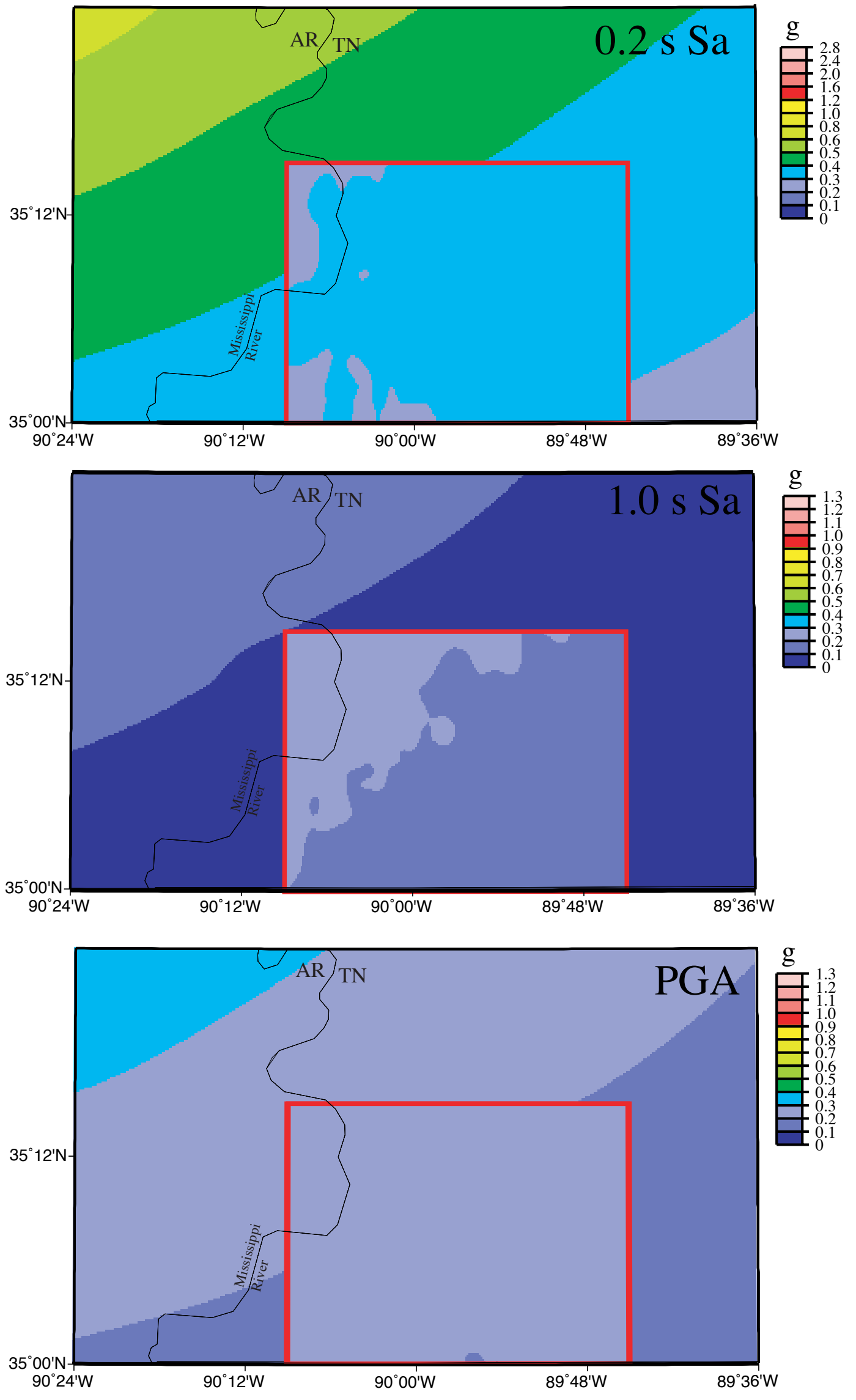

Figure 13 

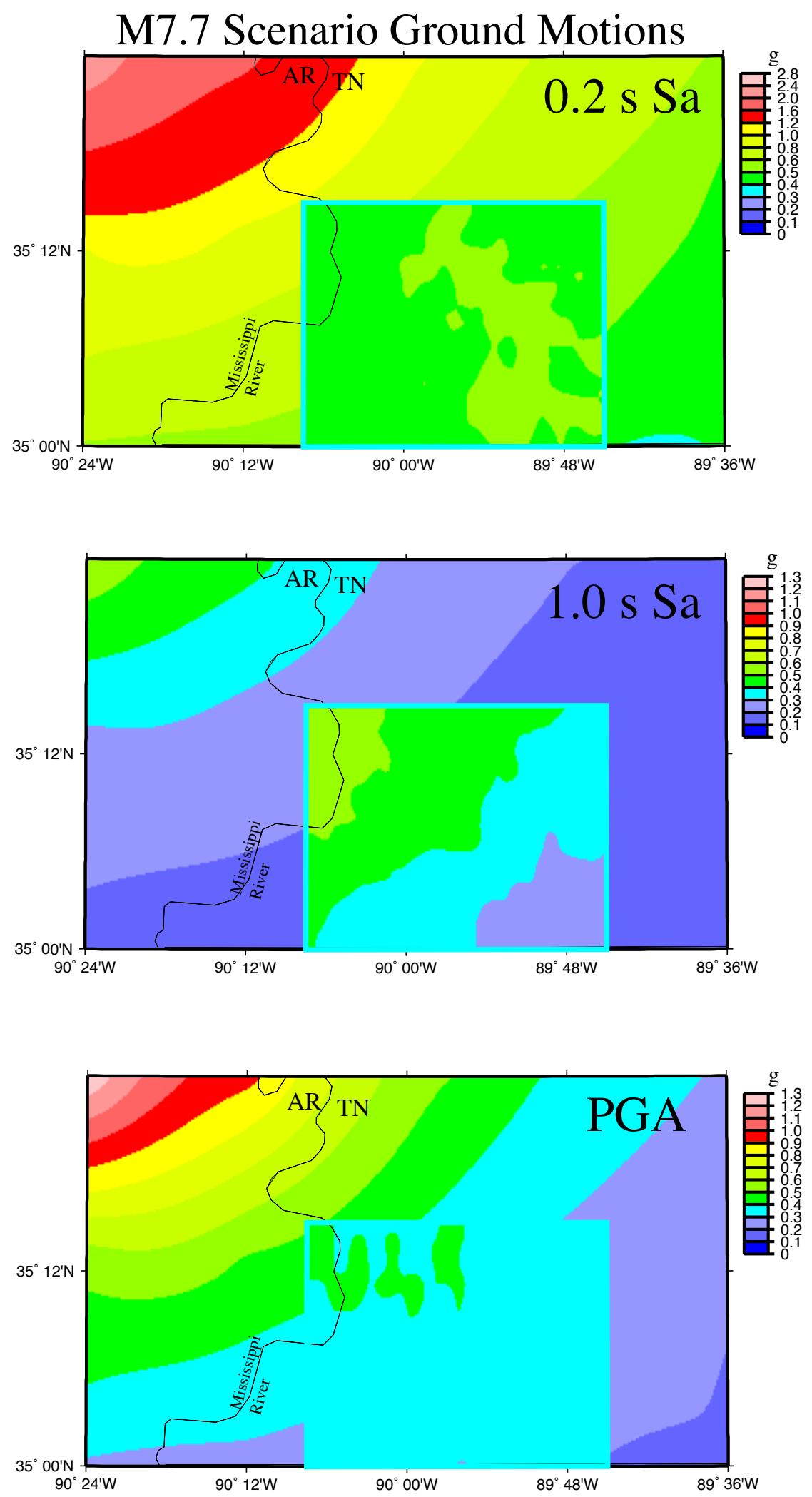


\section{M6.2 Scenario Ground Motions}
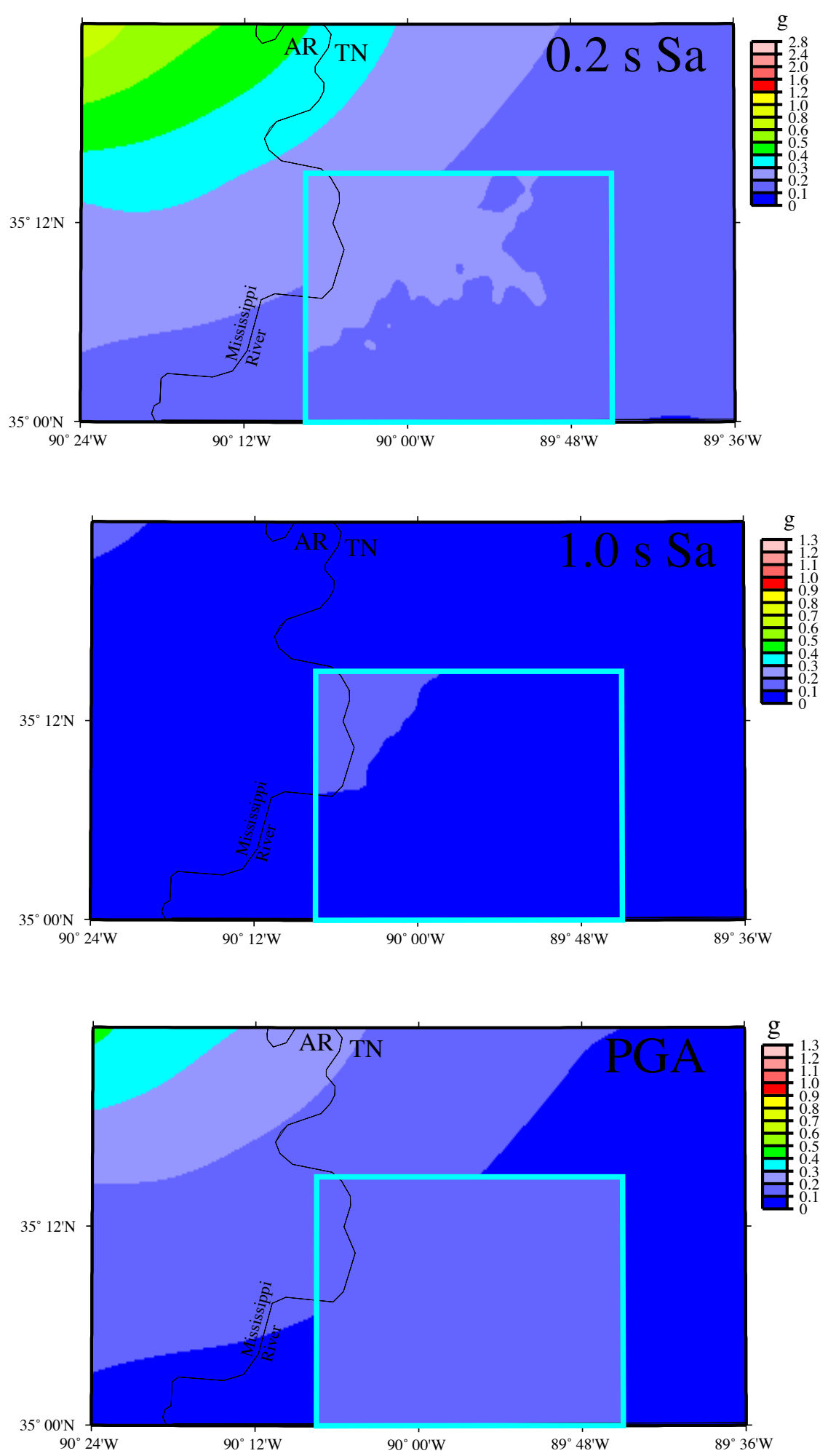
Site-Amplification Sensitivities
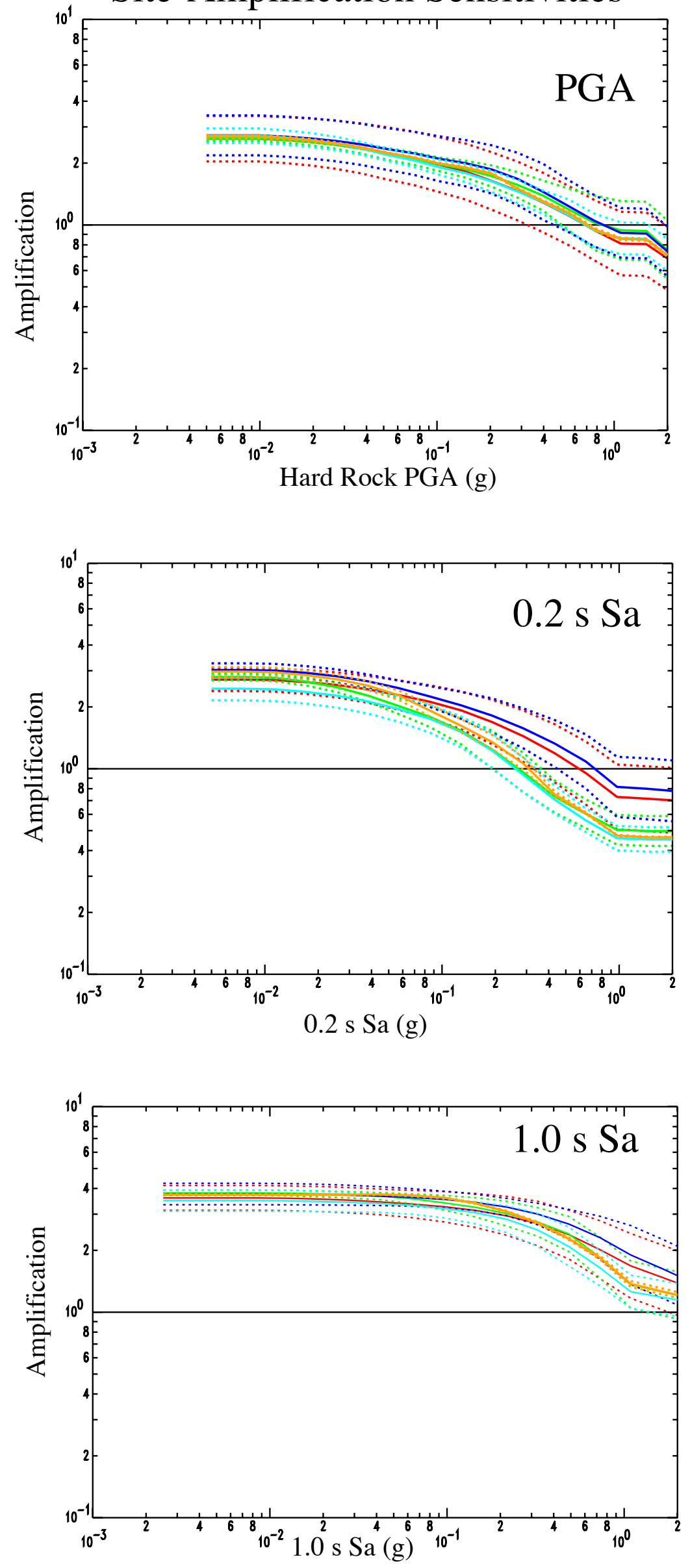

Figure 16 

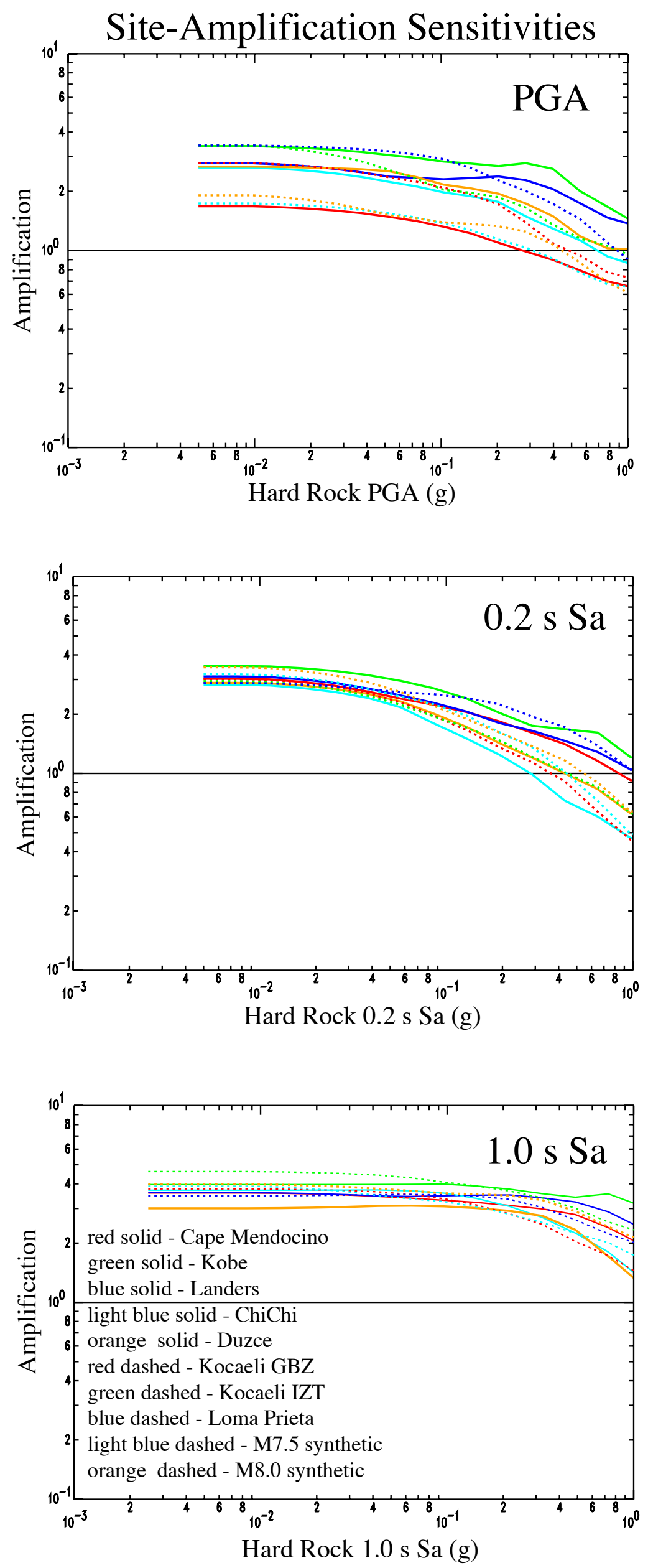

Figure 17 


\section{Site-Amplification Sensitivities}

\section{PGA}
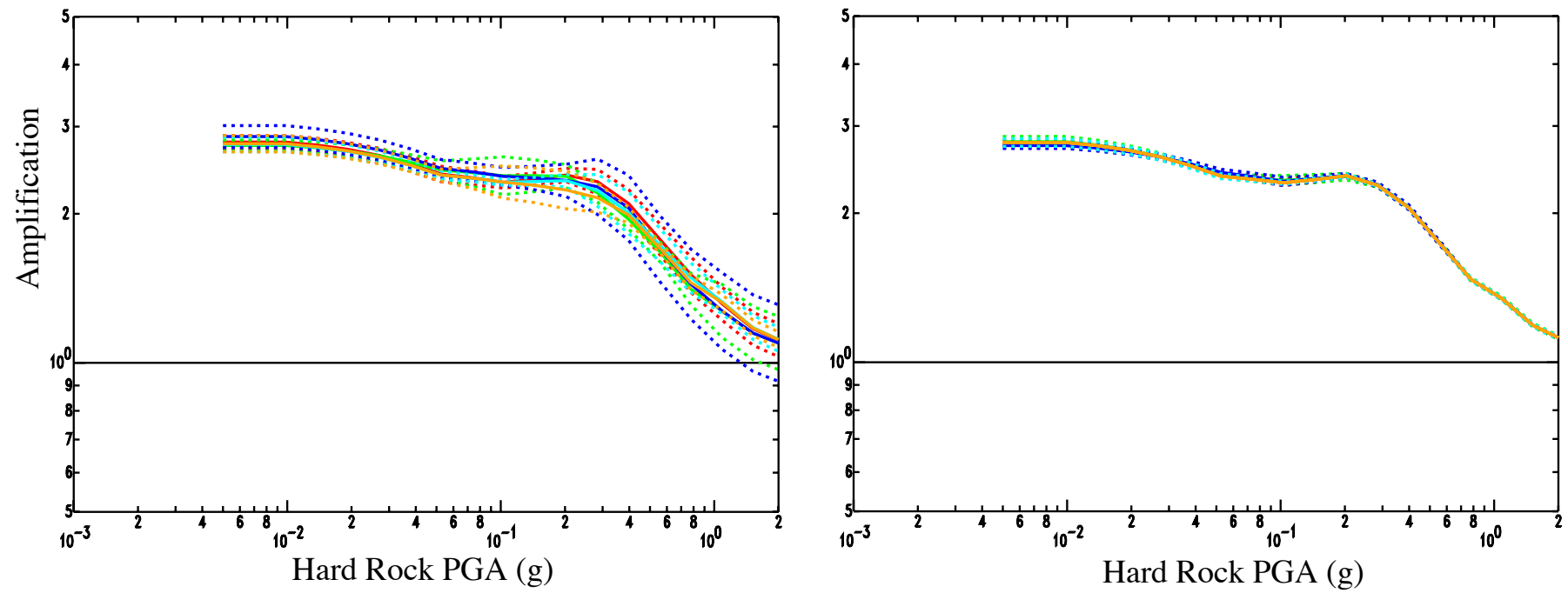

$0.2 \mathrm{~s} \mathrm{Sa}$
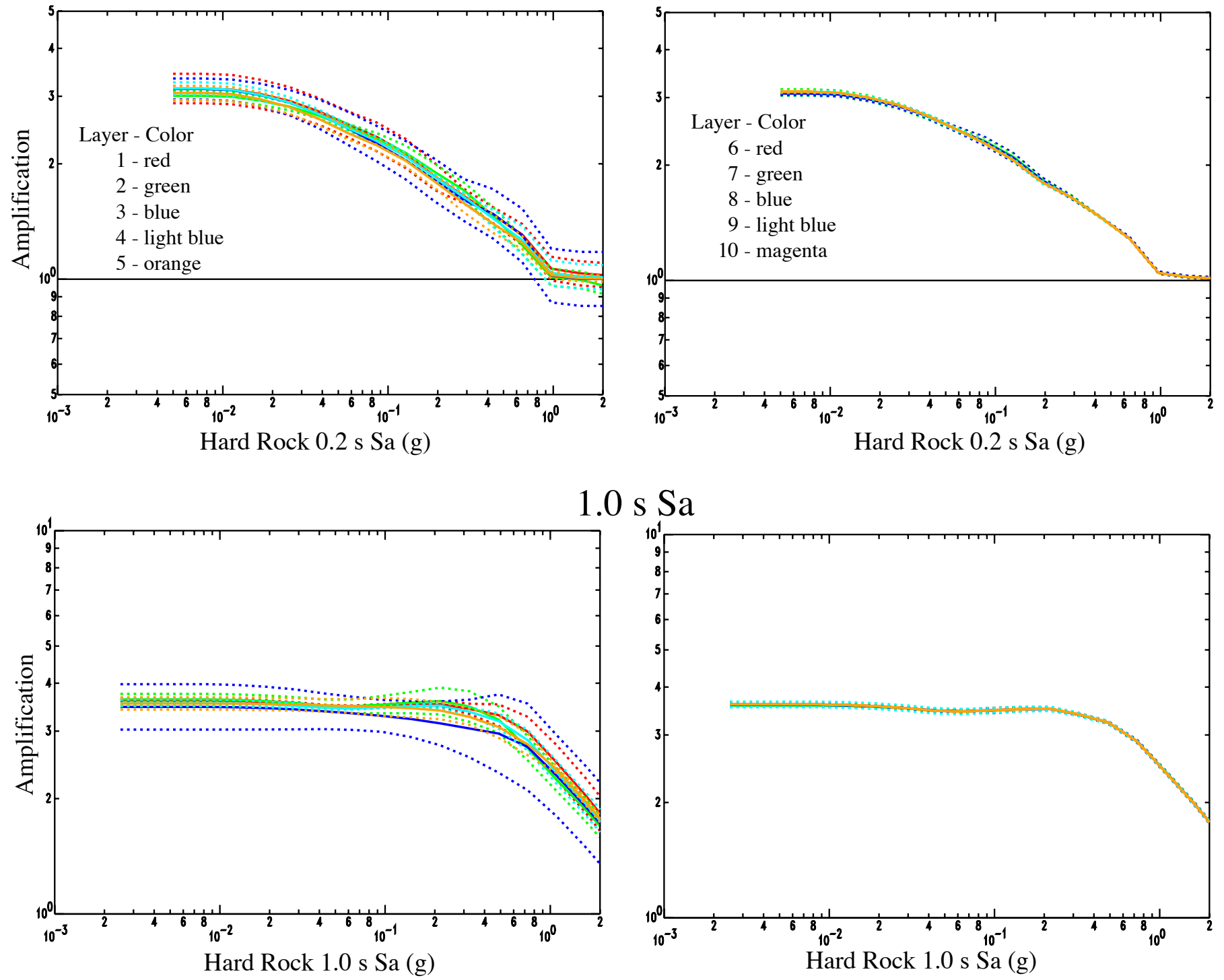

$1.0 \mathrm{~s} \mathrm{Sa}$

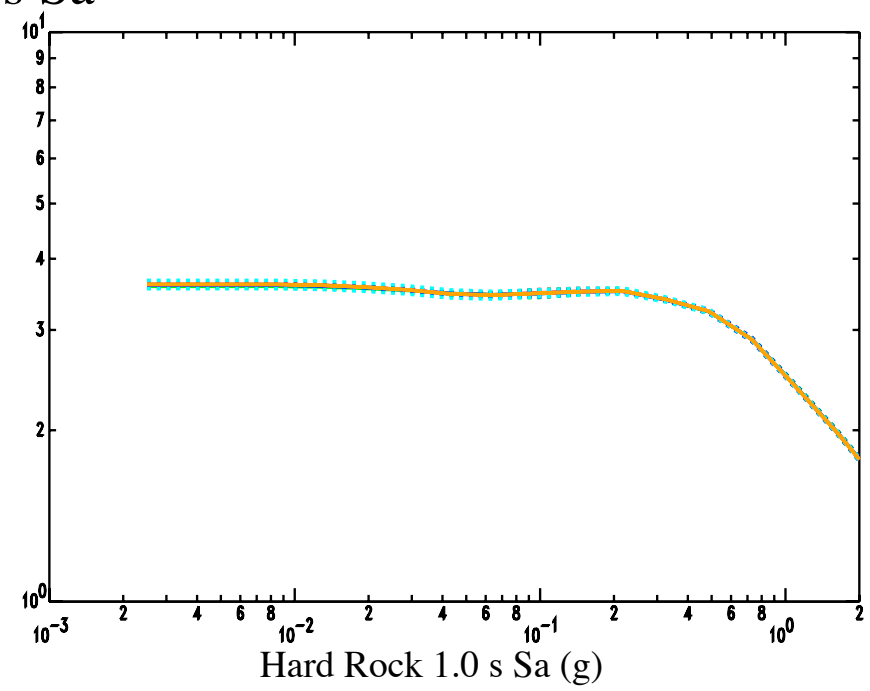

Figure 18 


\section{Site-Amplification Sensitivities}

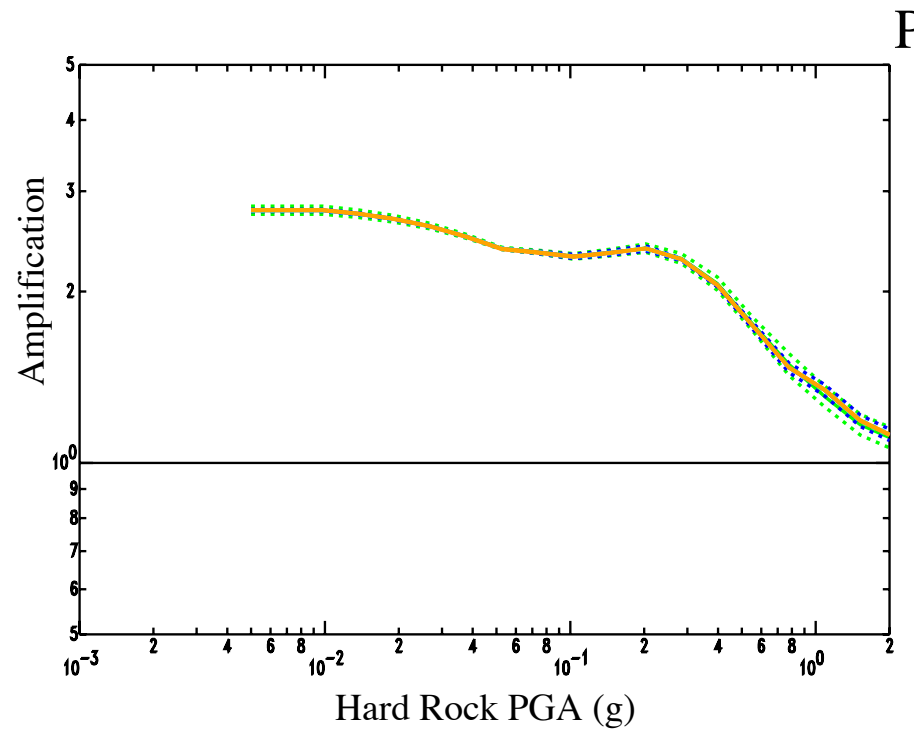

PGA

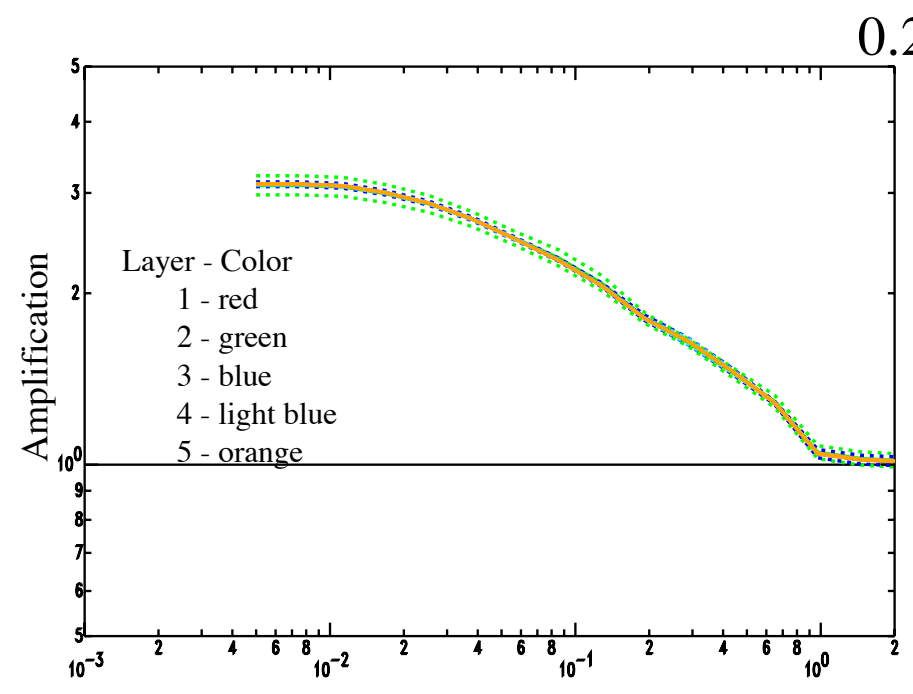

Hard Rock 0.2 s Sa (g)

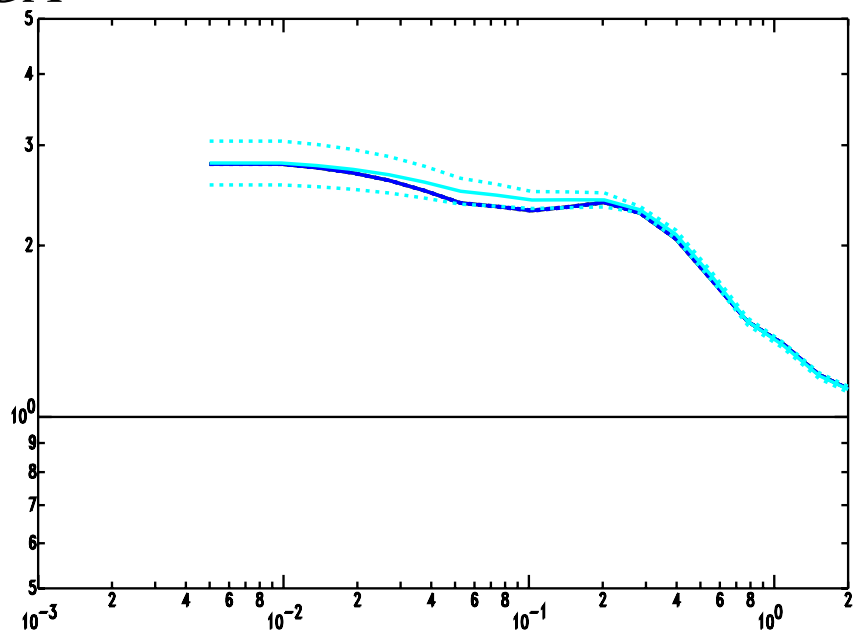

Hard Rock PGA (g)

$0.2 \mathrm{~s} \mathrm{Sa}$

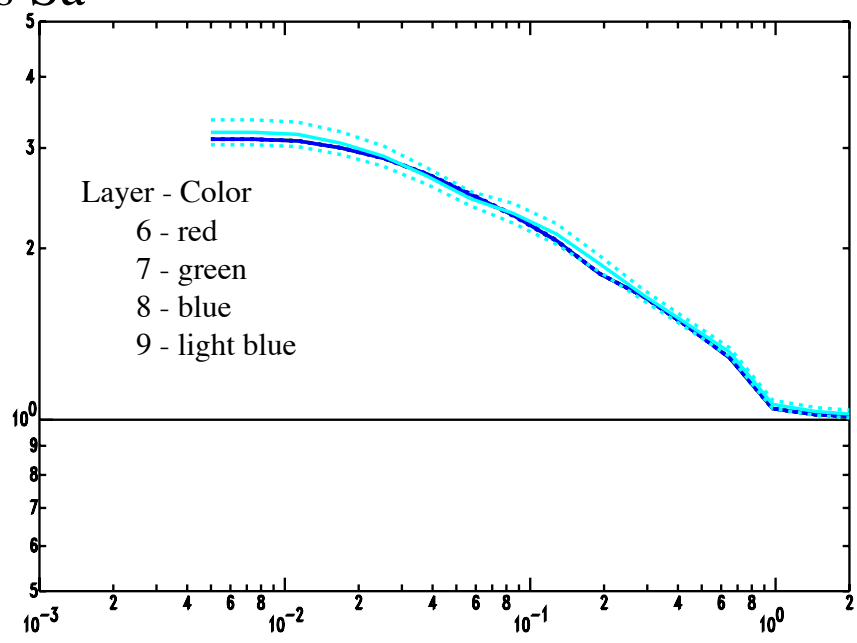

Hard Rock 0.2 s Sa (g)

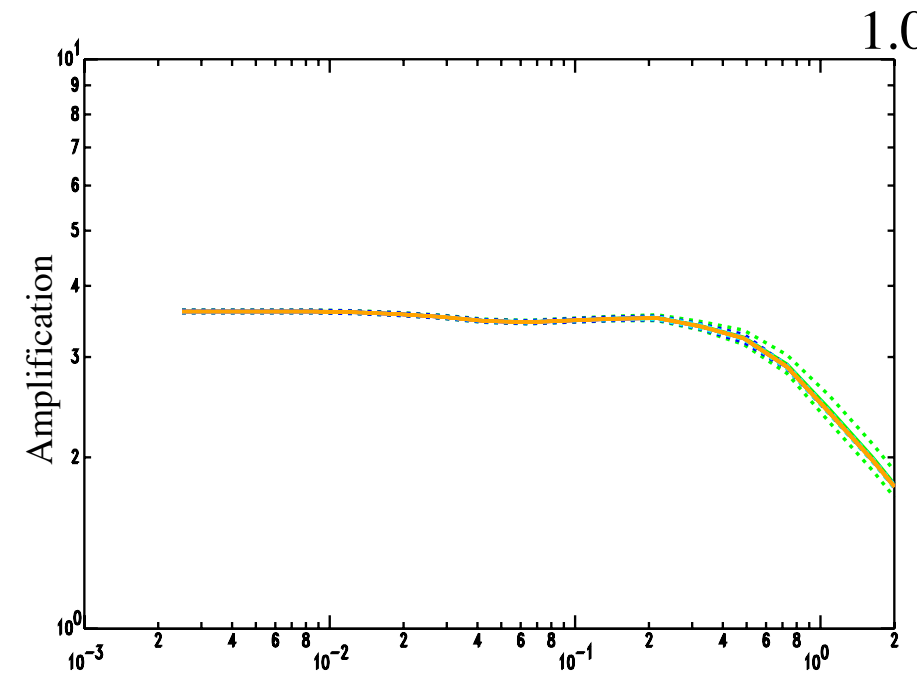

Hard Rock 1.0 s Sa (g)

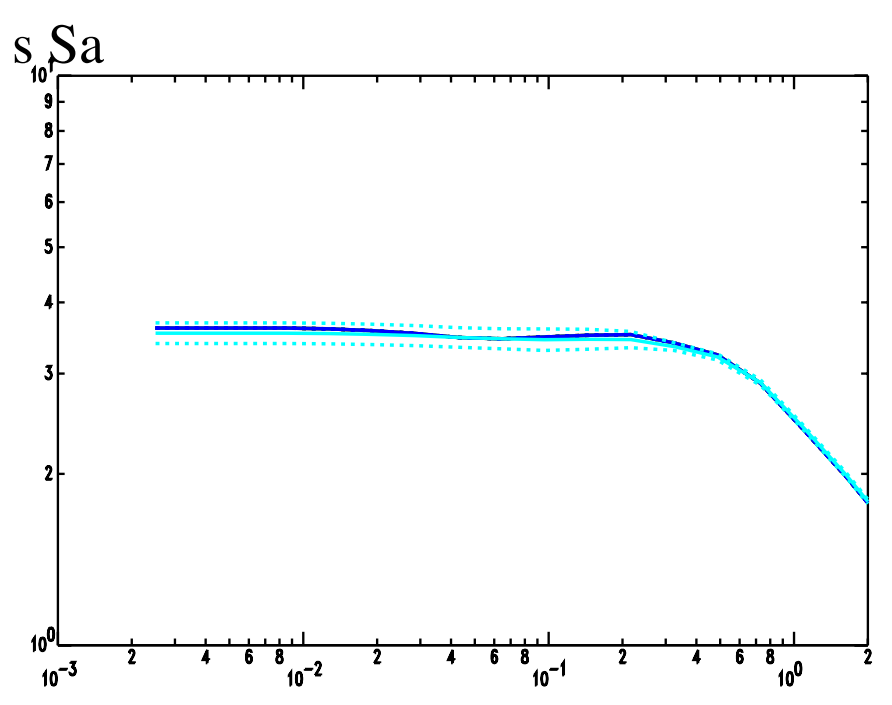

Hard Rock 1.0 s Sa (g)

Figure 19 


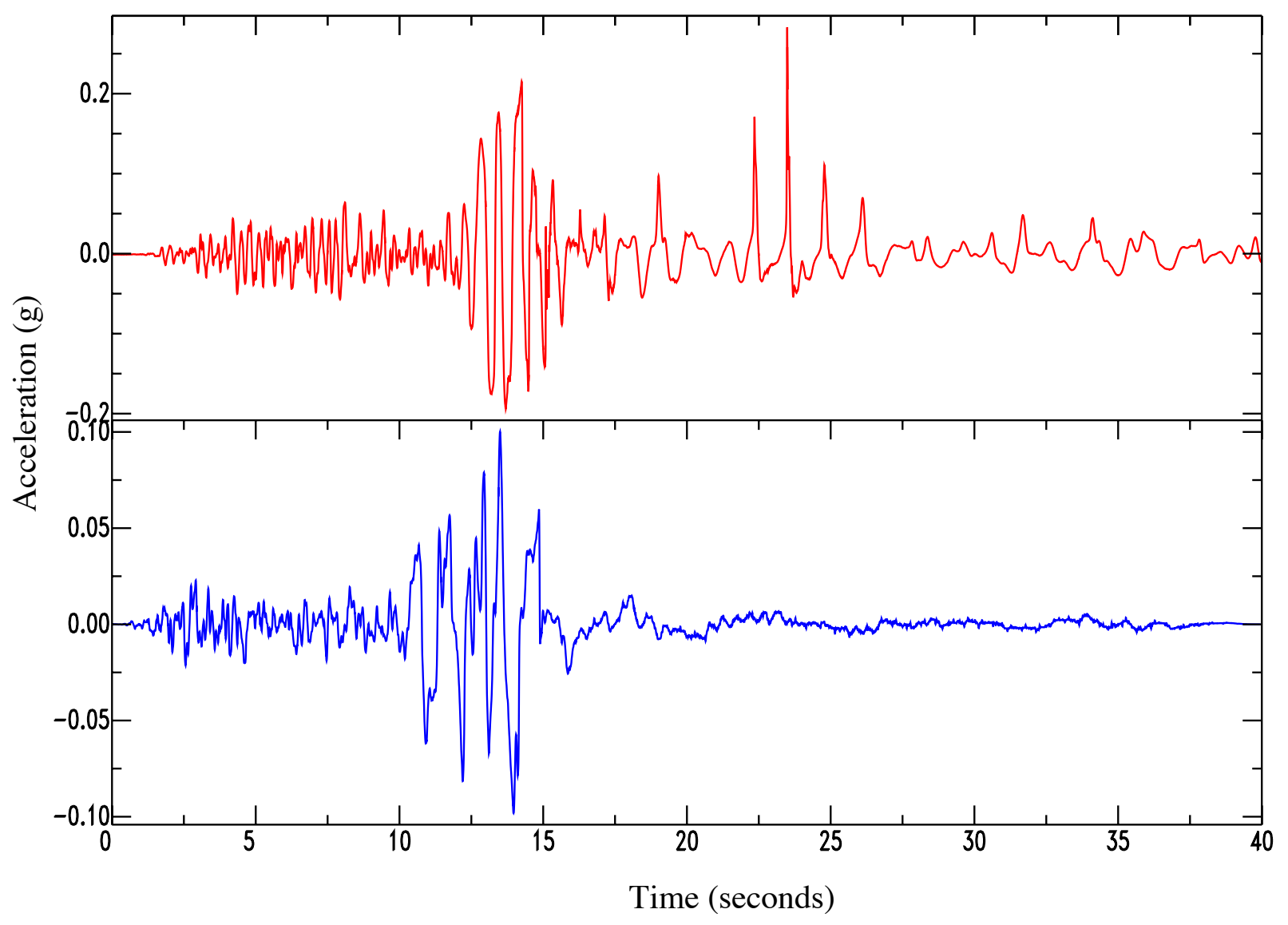

Figure 20 